\title{
Analysis of the effect of intake plenum design on the scavenging process in a 2- Stroke Boosted Uniflow Scavenged Direct Injection Gasoline (BUSDIG) Engine
}

\author{
Author, co-author (Do NOT enter this information. It will be pulled from participant tab in \\ MyTechZone) \\ Affiliation (Do NOT enter this information. It will be pulled from participant tab in MyTechZone)
}

Copyright () 2017 SAE International

\begin{abstract}
In this study, the effect of the intake plenum design on the scavenging process in a newly proposed 2-stroke Boosted Uniflow Scavenged Direct Injection Gasoline (BUSDIG) engine was studied in detail by three dimensional (3D) computational fluid dynamics (CFD) simulations. In the BUSDIG engine, the intake scavenge ports are integrated into the cylinder liner and their opening and closure are controlled by the movement of piston top while exhaust valves are placed in the cylinder head. In order to accommodate the optimized scavenge ports in the real engine application, the intake plenum with an inlet pipe and a scavenge chamber was designed and connected to the 12 evenly distributed scavenge ports in a single cylinder BUSDIG engine. In order to achieve optimal scavenge performances and sufficient in-cylinder flow motions to enhance the fuel/air mixing, five design parameters of the intake plenum were investigated, including the ratio of the inlet area relative to the scavenge port area $\left(r_{I / S}\right)$, the radius of the round connecting the inlet pipe and the scavenge chamber $\left(r_{R}\right)$, the ratio of the scavenge chamber volume to the cylinder displacement volume $\left(r_{S / C}\right)$, the angle between the inlet pipe and exhaust pipe $\left(\alpha_{I / E}\right)$ and the ratio of bore to the scavenge port length $\left(r_{B / P L}\right)$. It is found that the best scavenging performance is achieved at low engine speed when the intake plenum design shows less impact on the scavenging performances. As the engine speed increases, the impact on the scavenging performance by the intake plenum design becomes more significant. There is a trade-off between the tumble ratio (TR) and cross tumble ratio (CTR) for each intake plenum design. Based on the systematic study carried out, the intake plenum design parameters were optimized for high scavenging performance and strong large scale flow motions in the BUSDIG engine.
\end{abstract}

\section{Introduction}

The engine downsizing and downspeeding technologies have been developed in automotive industry to reduce $\mathrm{CO}_{2}$ emissions and achieve higher engine efficiency. However, further engine downsizing and downspeeding by increasing boost in the 4-stroke gasoline engine are hampered by the increased peak cylinder pressure, knocking combustion and associated higher thermal and mechanical load. Alternatively, the 2-stroke engine has the potential to achieve both downsizing and downspeeding because of its doubled firing frequency which requires a lower IMEP and lower peak in-cylinder pressure at the same output toque than a 4-stroke counterpart. The additional advantages, including the higher power-to-weight ratio and compact engine dimension, make the 2-stroke engine naturally suitable for aggressive engine downsizing and downspeeding to increase the power density and improve fuel economy.

In order to take full advantage of the 2-stroke cycle operation, a novel 2-stroke Boosted Uniflow Scavenged Direct Injection Gasoline (BUSDIG) engine [1] was proposed to achieve aggressive engine downsizing and downspeeding. The scavenging process, during which the fresh intake charge displaces the burned gas from the previous cycle and fills the cylinder for the next cycle, is essential for the 2-stroke cycle operation. Because of the long overlapping period of intake and exhaust processes in the 2-stroke operation, the intake fresh mixture can flow directly into the exhaust port during the scavenging process, i.e. the charge short-circuiting phenomenon. Therefore, the uniflow scavenge method, which has been proved to be most effective in the scavenging performance of the 2-stroke operation [2, 3], is adopted in the BUSDIG engine. The intake ports are integrated into the cylinder liner and their opening and closure are controlled by the movement of the piston top while exhaust valves are placed in the cylinder head. The variable valve actuation (VVA) technology is applied to the exhaust valves to control the scavenging process under different boost pressures at various engine speeds. Meanwhile, the BUSDIG engine can also minimize the bore distortion caused by uneven thermal loading in the conventional ported 2-stroke engine with cold intake port on one side and hot exhaust port on the other, thus improving the engine durability.

In order to maximize the scavenge performance and optimize the incylinder flow motion, the three dimensional (3D) computational fluid dynamics (CFD) simulations were performed in a previous work [4] to optimize two key scavenge port angles, i.e. Axis Inclination Angle (AIA) and Swirl Orientation Angle (SOA), in the BUSDIG engine. In addition to the scavenge port design, the intake plenum, which is used to accommodate the scavenge ports and connected to the intake air system, e.g. boost system, also affects the scavenging process and in-cylinder flow motions. Laget et al. [2] performed simulations to investigate the scavenging process in a 2 -stroke uniflow diesel engine with and without the intake plenum. They found that the use of a toric intake plenum induces a non-identical feeding of each of the 12 scavenge ports and results in a skewness of the flow. Abis et al. [5] found that a larger intake plenum volume can provides a constant pressure for the scavenging and the gas dynamics due to the opening of the intake ports can be damped considerably. Hori [6] investigated the effect of the entrance radius of the scavenging port in the intake 
plenum and found an entrance radius of $3 \mathrm{~mm}$ is appropriate, because a larger radius leads to flow detachment at the entrance and a loss of effective area and a smaller radius increases pressure loss at the entrance. Vashishtha et al. [7] investigated the design of inlet entry orientation for the intake plenum in a 2-stroke gasoline engine, and found that the inlet entry in-line with the cylinder axis shows better scavenging performance than the inlet entry perpendicular to cylinder axis. In addition to the toric design, the intake plenum with a scroll design is thought to be the best method of assisting the angled scavenge ports to induce the swirling flow [8]. However, this design is difficult to incorporate into multi-cylinder designs with close intercylinder spacing.

In this study, in order to design an optimal intake plenum to achieve good scavenging performance and sufficient in-cylinder flow motions in the BUSDIG engine, five design parameters of the intake plenum were investigated by 3D CFD simulations, including the ratio of the inlet area relative to the scavenge port area $\left(r_{I / S}\right)$, the radius of the round connecting the inlet pipe and the scavenge chamber $\left(r_{R}\right)$, the ratio of the scavenge chamber volume to the cylinder displacement volume $\left(r_{S / C}\right)$, the angle between the inlet pipe and exhaust pipe $\left(\alpha_{I / E}\right)$ and the ratio of bore to the scavenge port length $\left(r_{B / P L}\right)$. The effect of each design parameter on the in-cylinder flow and scavenging process was analysed at different engine speeds. Based on the current study, the optimized intake plenum can be designed for high scavenging efficiency and strong large scale flow motions.

\section{Engine specifications}

Figure 1 shows schematically the design of the cylinder head, piston crown shape and scavenge ports (without intake plenum). Based on the initial design of bore/stroke for maximum performance [4], a pent roof cylinder head is adopted in the current design to accommodate two exhaust valves, a central mounted direct injection (DI) gasoline injector and a spark plug. A shallow bowl is included in the centre of piston top to guide the fuel jets from the DI injector as well as to avoid the clash with the spark plug.
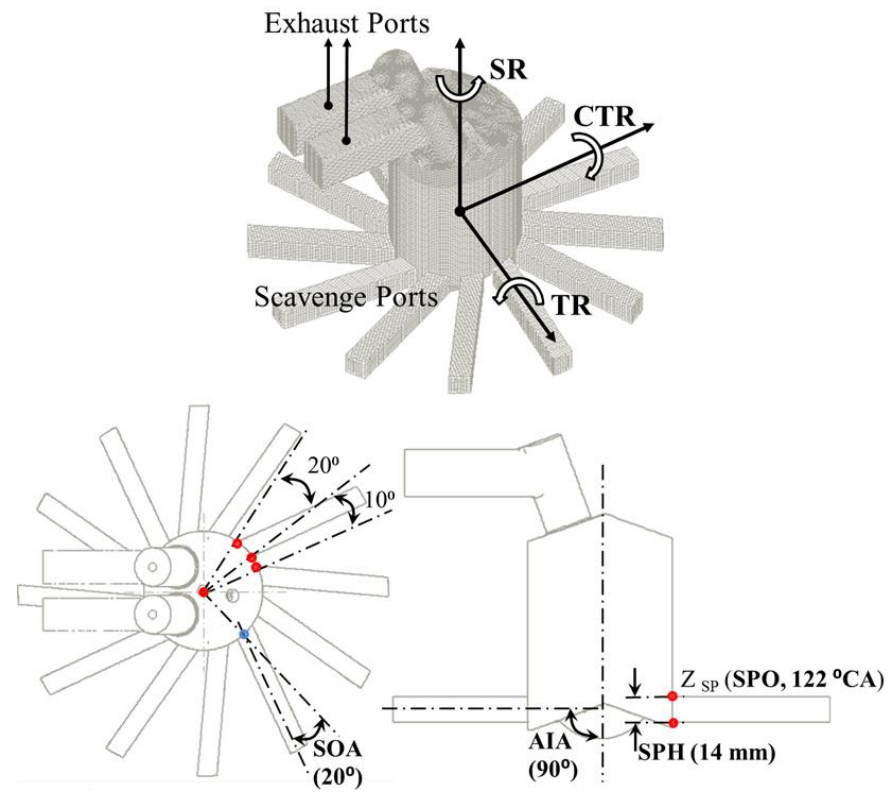

Figure 1. Layout of the BUSDIG engine with 12 evenly distributed scavenge ports and the definitions of swirl ratio (SR), tumble ratio (TR) and cross tumble ratio (CTR).
Twelve evenly distributed scavenge ports are integrated to the cylinder to introduce the fresh charge and scavenge out the residual burnt gas. A single scavenge port occupies a $20^{\circ}$ segment on the cylinder circumference and the interval between two adjacent scavenge ports is fixed at $10^{\circ}$. Figure 1 also shows the design parameters of the scavenge port, including the axis inclination angle (AIA), swirl orientation angle (SOA), scavenge port opening (SPO) timing and scavenge port height (SPH). Based on the previous study [4], the AIA and SOA are fixed at $90^{\circ}$ and $20^{\circ}$ respectively, the SPH at $14 \mathrm{~mm}$ and the SPO at $122{ }^{\circ} \mathrm{CA}$. The exhaust valve duration (ED) and opening timing (EVO) are fixed at $126{ }^{\circ} \mathrm{CA}$ and $117{ }^{\circ} \mathrm{CA}$ respectively. Figure 2 shows the normalized scavenge port opening area (SA') profiles and normalized exhaust valve lift (EL') profiles. The intake pressure is fixed at 2 bar (absolute). The other engine specifications are shown in Table 1.

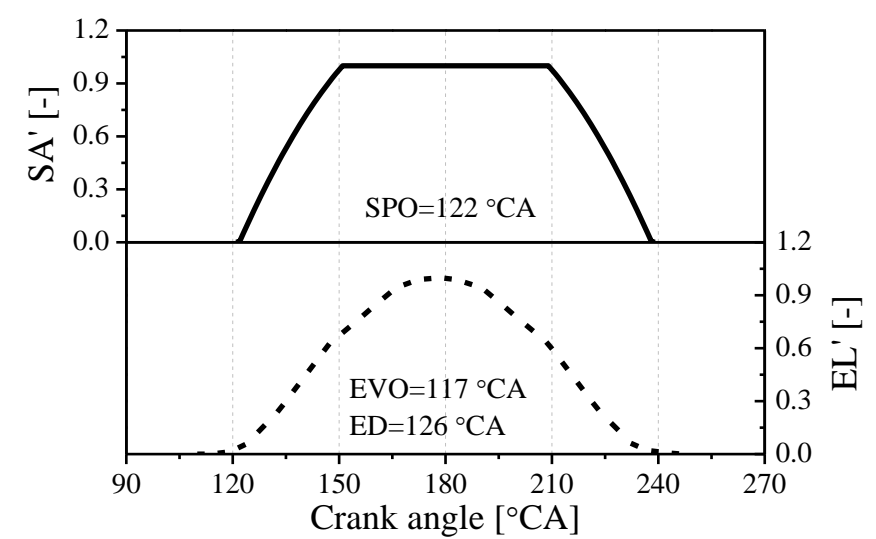

Figure 2. Schematic diagram of the normalized exhaust valve lift profiles (EL') and scavenge area (SA') profiles.

Table 1. Specifications of the BUSDIG engine.

\begin{tabular}{|l|l|}
\hline Bore & $80 \mathrm{~mm}$ \\
\hline Stroke & $100 \mathrm{~mm}$ \\
\hline Connecting rod & $180 \mathrm{~mm}$ \\
\hline Displacement & $0.5 \mathrm{~L}$ \\
\hline Compression ratio & $14: 1$ \\
\hline Cylinder head & $\begin{array}{l}\text { Pent roof with 2 exhaust valves, a DI } \\
\text { injector and a spark plug }\end{array}$ \\
\hline Piston & Shallow bowl in the centre \\
\hline
\end{tabular}

\section{Design of the intake plenum}

In order to accommodate the scavenge ports, the intake plenum with an inlet pipe and a scavenge chamber was designed and connected to the 12 evenly distributed scavenge ports in the single cylinder BUSDIG engine. In this study, five design parameters of the intake plenum are investigated and optimized in detail to optimize the scavenging performances and in-cylinder flow motions in the 2stroke BUSDIG engine. The plenum design is shown in Figure 3 and the design parameters are defined as follows.

(1) $r_{I / S}$ is defined to demonstrate the design of the inlet area relative to the scavenge port area and computed by Equation (1):

$$
r_{I / S}=\frac{\text { Inlet area }}{\text { Total scavenge port area }}
$$

Page 2 of 16 
In this study, the width of inlet pipe was kept constant while the height of the inlet pipe was increased from 20 to $40 \mathrm{~mm}$, and the corresponding $r_{I / S}$ increased from 0.68 to 1.36 .

(2) $r_{R}$ is the radius of the round connecting the inlet pipe and the scavenge chamber.

(3) $r_{S / C}$ is defined to demonstrate the design of the scavenge chamber volume relative to the cylinder displacement volume and computed by Equation (2):

$$
r_{S / C}=\frac{\text { scavenge chamber volume }}{\text { cylinder displacement volume }}
$$

The scavenge chamber height was kept constant while the width is increased from $22 \mathrm{~mm}$ to $60 \mathrm{~mm}$, and the corresponding $r_{S / C}$ increased from 0.84 to 3.02 .

(4) $\alpha_{I / E}$ is defined as the angle between the inlet pipe and exhaust pipe to demonstrate the design of relative orientation between inlet and exhaust pipes. Three $\alpha_{I / E}$ values, i.e. $180^{\circ}, 90^{\circ}$ and $0^{\circ}$, are investigated in this study.

(5) $r_{B / P L}$ is defined to demonstrate the design of the scavenge port length (PL) in radial direction and computed by Equation (3).

$$
r_{B / P L}=\frac{\text { cylinder bore }}{\text { scavenge port length }}
$$

The scavenge port length was increased from $5 \mathrm{~mm}$ to $20 \mathrm{~mm}$, and the corresponding $r_{B / P L}$ decreased from 16 to 4 .

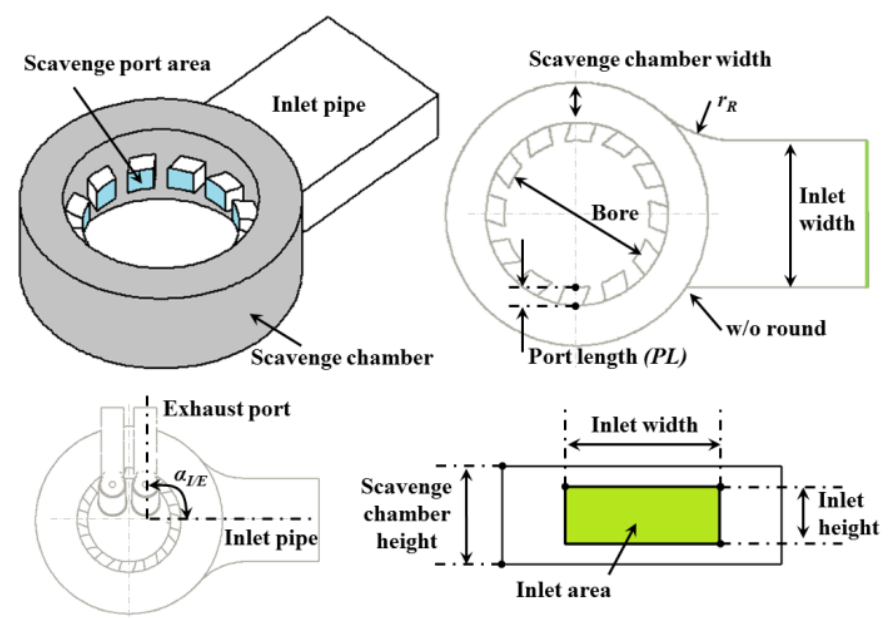

Figure 3. Schematic diagram of the intake plenum design.

\section{Simulation setup}

\section{Numerical models}

In this study, the CFD software, STAR-CD [9], was adopted to perform the simulations. The Reynolds-Averaged Navier Stokes (RANS) approach was applied with RNG k- $\varepsilon$ turbulence model in the simulations. The heat transfer was implemented through the general form of the enthalpy conservation equation for the fluid mixture. The Angelberger wall function was used for the simulation of the wall heat transfer. The Pressure-Implicit with Splitting of Operators (PISO) algorithm was used to solve the equations. The equations of momentum, turbulence kinetic energy and turbulence dissipation were discretized with the monotone advection and reconstruction scheme (MARS). The upwind differencing scheme (UD) and central differencing scheme (CD) were applied to discretize the temperature and density equations, respectively. The residual tolerance for the momentum, turbulence kinetic energy and turbulence dissipation was set at 0.001 while the residual tolerance for pressure and temperature was set at 0.0001 to achieve good compromise between convergence and computational time. The angular time-step in the simulations was fixed at 0.1 degree crank angle.

\section{Simulation conditions}

The one dimensional (1D) simulations were performed using 1D engine simulation program WAVE to obtain the realistic fired engine conditions for the CFD simulations of the scavenging process in the BUSDIG engine. The adopted initial and boundary conditions in CFD simulations are shown in Table 2. Different wall temperature values of the cylinder head, piston top and cylinder liner were used according to the estimation provided in [10]. The initial mixture components in the cylinder and exhaust ports at $100{ }^{\circ} \mathrm{CA}$ after top dead center (ATDC) are pure burned gas, i.e. $\mathrm{CO}_{2}, \mathrm{H}_{2} \mathrm{O}$ and $\mathrm{N}_{2}$. The mixture components in the intake plenum and inlet boundary are pure air, i.e. $\mathrm{O}_{2}$ and $\mathrm{N}_{2}$. The CFD simulations were performed from 100 ${ }^{0} \mathrm{CA}$ ATDC to $280{ }^{\circ} \mathrm{CA}$ ATDC, which covers the whole period of the scavenging process.

Table 2. Simulation conditions.

\begin{tabular}{|l|l|}
\hline Initial conditions $@ 100^{\circ} \mathbf{C A}$ ATDC & $1665 \mathrm{~K}$ \\
\hline Cylinder temperature & $8.6 \mathrm{bar}$ \\
\hline Cylinder pressure & $350 \mathrm{~K}$ \\
\hline Intake temperature & $2 \mathrm{bar}$ \\
\hline Intake pressure & $800 \mathrm{~K}$ \\
\hline Exhaust temperature & $1.06 \mathrm{bar}$ \\
\hline Exhaust pressure & \\
\hline Boundary conditions & $350 \mathrm{~K}$ \\
\hline Intake temperature & $2 \mathrm{bar}$ \\
\hline Intake pressure & $800 \mathrm{~K}$ \\
\hline Exhaust temperature & $1.06 \mathrm{bar}$ \\
\hline Exhaust pressure & $440 \mathrm{~K}$ \\
\hline Cylinder head temperature & $522 \mathrm{~K}$ \\
\hline Piston top temperature & $384 \mathrm{~K}$ \\
\hline Cylinder liner temperature &
\end{tabular}

The engine mesh was generated in ES-ICE software and several cylinder cell layers of the moving mesh were automatically deleted/added during the compression/expansion stroke. The arbitrary sliding interface (ASI) was applied between the scavenge ports and the cylinder liner to control the attachment and detachment with the piston movement. ASI was also applied to control the connectivity between exhaust domains and cylinder domain with the movement of exhaust valves. Three different meshes with an average grid size of 2 $\mathrm{mm}, 1.6 \mathrm{~mm}$ and $1 \mathrm{~mm}$ were generated for the baseline engine design to investigate the sensitivity of simulation results to the mesh quality [4]. The results indicated that an intermediate grid size of $1.6 \mathrm{~mm}$ was sufficient to achieve a convergent result regarding in-cylinder pressure, temperature profiles, flow motions and scavenging performance. Thus, the engine mesh (including the intake plenum) with an average grid size of $1.6 \mathrm{~mm}$, has been used in the current study.

Page 3 of 16 


\section{Results and discussion}

\section{Effect of the ratio of inlet area to the total scavenge port area $\left(r_{I / S}\right)$}

In this section, the ratio of inlet area to the total scavenge port area $\left(r_{I / S}\right)$ is studied at first. The design parameters of the intake plenum are listed in Table 3.

Table 3.Intake plenum designs for the study on $r_{I / S}$.

\begin{tabular}{|l|l|l|l|l|l|}
\hline Case no. & $\boldsymbol{r}_{I / S}[-]$ & $r_{R}[\mathrm{~mm}]$ & $r_{S / C}[-]$ & $\alpha_{I / E}\left[{ }^{0}\right]$ & $r_{B / P L}[-]$ \\
\hline$\# 1$ & $\mathbf{0 . 6 8}$ & w/o & 0.84 & 180 & 8 \\
\hline$\# 2$ & $\mathbf{1 . 0 2}$ & w/o & 0.84 & 180 & 8 \\
\hline$\# 3$ & $\mathbf{1 . 3 6}$ & w/o & 0.84 & 180 & 8 \\
\hline
\end{tabular}

In order to characterize the scavenging performance of the 2-stroke BUSDIG engine, four scavenge parameters, i.e. delivery ratio (DR), trapping efficiency (TE), scavenging efficiency (SE) and charging efficiency (CE) are used in this study. The DR represents the ability to deliver the fresh change from the intake system. The CE is used to quantify the retained the fresh charge in the cylinder after the scavenging. The TE represents the ability to retain the fresh charge in the cylinder relative to the total delivered charge. And the SE is used to demonstrate the retained fresh charge mass relative to the total trapped in-cylinder mass. Generally, higher DR, TE, SE and CE indicate higher scavenging performances.

$$
\begin{aligned}
& D R=\frac{\text { delivered fresh charge mass }}{\text { reference } \text { mass }} \\
& T E=\frac{\text { mass of fresh charge retained in the cylinder }}{\text { delivered fresh charge mass }}=\frac{C E}{D R} \\
& S E=\frac{\text { mass of fresh charge retained in the cylinder }}{\text { mass of trapped cylinder charge }} \\
& C E=\frac{\text { mass of fresh charge retained in the cylinder }}{\text { reference mass }}
\end{aligned}
$$

The reference mass in above equations is calculated by the displaced volume multiplied by the ambient air density.

As shown in Figure 4, the longer scavenging duration at low engine speed of $1000 \mathrm{rpm}$ leads to better scavenging performances of higher $\mathrm{DR}, \mathrm{SE}$ and CE, which in turn minimizes the differences of scavenging performances among different inlet area designs. The SE and $\mathrm{CE}$ with different $r_{I / S}$ values are around 1 and 1.4 respectively at $1000 \mathrm{rpm}$, and the DR shows a slight increasing trend with $r_{I / S}$, as shown in Figure 4 (a). As the engine speed increases to $2000 \mathrm{rpm}$, the DR value is reduced for each inlet area design due to shortened scavenge duration. Correspondingly, the $\mathrm{CE}$ and $\mathrm{SE}$ are also decreased. The SE is the same at 0.95 for each design, while the DR and $\mathrm{CE}$ for the design with the largest $r_{I / S}$ value of 1.36 are highest. A further increase in the engine speed to $3000 \mathrm{rpm}$ significantly decrease the scavenge duration, which further decreases the DR, SE and $\mathrm{CE}$ for each design. It is noted in Figure 4 (c) that larger $r_{I / S}$ values lead to higher DR, SE and CE values at the engine speed of $3000 \mathrm{rpm}$.

\section{Page 4 of 16}
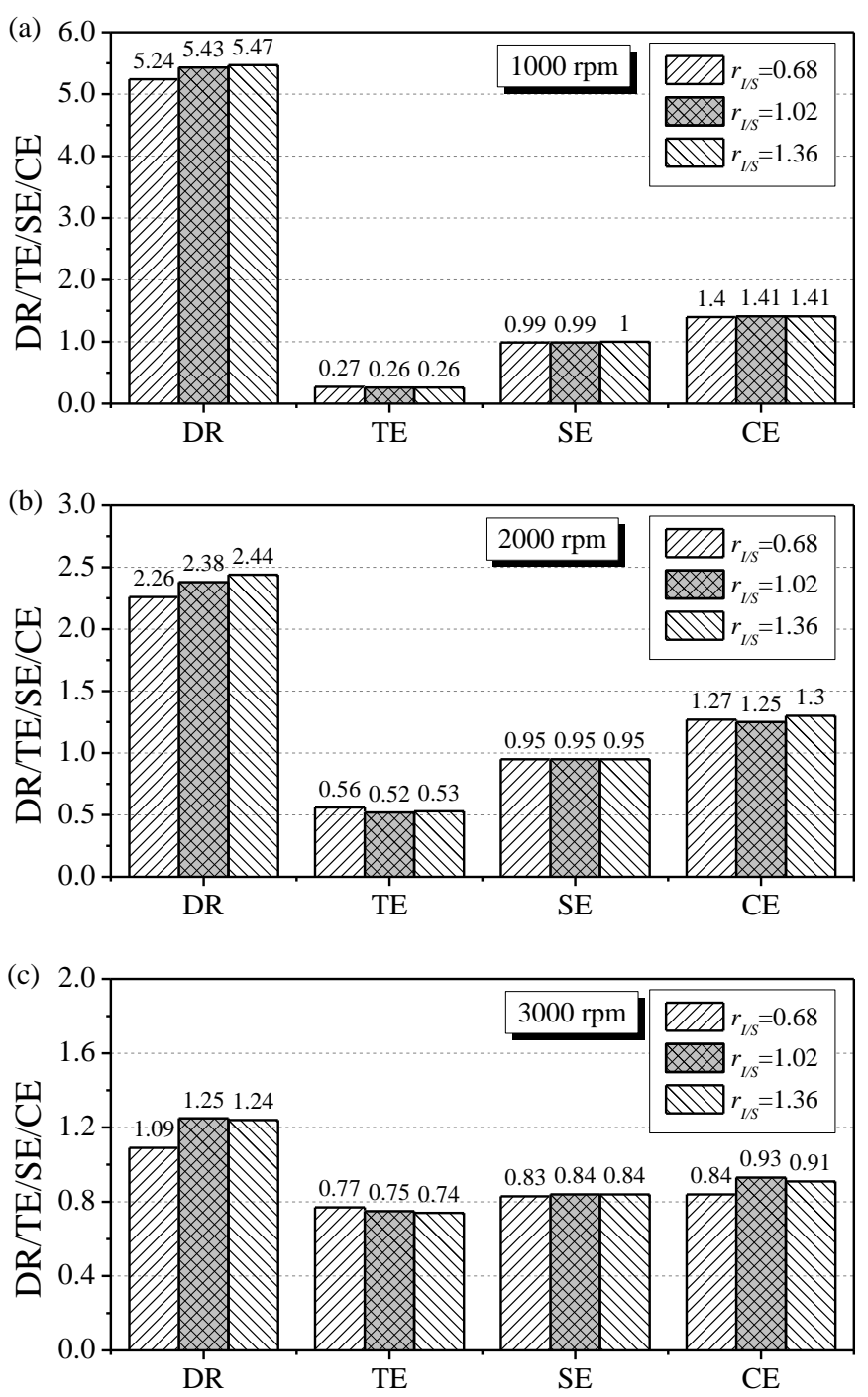

Figure 4. Effect of $r_{I / S}$ on scavenge performances at (a) $1000 \mathrm{rpm}$, (b) 2000 rpm and (c) $3000 \mathrm{rpm}$

In order to understand the effect of the $r_{I / S}$ value on the scavenge performances, the in-cylinder charge mass profiles are plotted in Figure 5. It is noted that the smallest inlet area design with $r_{I / S}$ of 0.68 shows slowest charging process at each engine speed. The charging process with $r_{I / S}$ of 1.02 and 1.36 are similar but a larger inlet area design leads to a higher peak in-cylinder mass at low engine speeds of $1000 \mathrm{rpm}$ and $2000 \mathrm{rpm}$, thus leading to the higher DR. In addition, the in-cylinder charge mass gradually decreases after the peak value when the balance of the pressure between the intake plenum and the cylinder is achieved. As a result, the final trapped in-cylinder charge mass is almost the same at $1000 \mathrm{rpm}$, leading to similar CE and SE. The inlet area design with $r_{I / S}$ of 1.36 has slightly higher final incylinder charge mass at $2000 \mathrm{rpm}$, thus slightly higher CE.

At $3000 \mathrm{rpm}$, the in-cylinder charge mass profiles overlap each other from bottom dead center (BDC) for the designs with $r_{I / S}$ of 1.02 and 1.36. The shortened scavenge duration at the higher engine speed significantly slows down the charging process and no spike is observed for all designs. This in turn leads to higher DR and CE for the designs with $r_{I / S}$ of 1.02 and 1.36 than that with $r_{I / S}$ of 0.68 . The $r_{I / S}$ has less impact on the SE. 

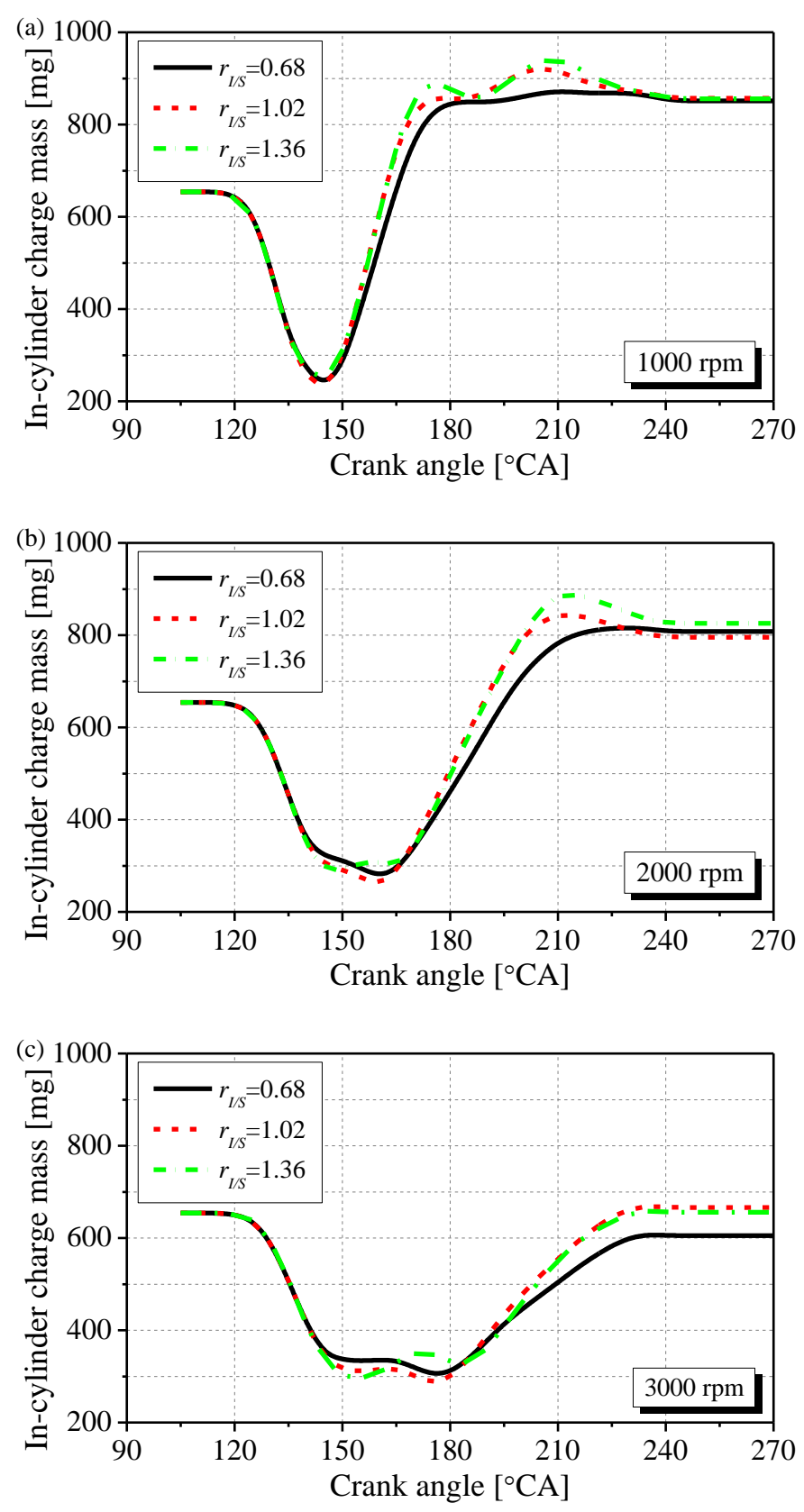

Figure 5. In-cylinder charge mass profiles for different $r_{I / S}$ at (a) $1000 \mathrm{rpm}$, (b) $2000 \mathrm{rpm}$ and (c) $3000 \mathrm{rpm}$.

In order to quantify the in-cylinder flow motions, the swirl ratio (SR) is calculated by the following equation:

$S R(\theta)=\frac{\sum_{i}^{m} v_{i}(\theta) r_{i}(\theta) V_{i}(\theta) \rho_{i}(\theta)}{\frac{2 \pi n}{60} \sum_{i}^{m} r_{i}(\theta)^{2} V_{i}(\theta) \rho_{i}(\theta)}$

where $n$ is the engine speed [rpm], $\theta$ the crank angle, $i$ the cell number, $V_{i}(\theta)$ the cell volume, $\rho_{i}(\theta)$ the cell density, $v_{i}(\theta)$ and $r_{i}(\theta)$ are the tangential velocity and radius respectively in the cylindrical coordinate with $z$ axis as the swirl axis.

Similarly, the tumble ratio (TR) and cross tumble ratio (CTR) are determined by replacing the swirl axis along with the cylindrical coordinate system in Equation (8) with the tumble/cross tumble axis.

Page 5 of 16
The tumble/cross tumble axis is parallel to $y / x$ axis and crosses the central point between maximum and minimum $\mathrm{z}$ value of the cylinder [11]. The direction of each flow motion has been marked in Figure 1.

Figure 6 shows the effect of $r_{I / S}$ on in-cylinder flow motions at 280 ${ }^{\circ} \mathrm{CA}$ with different engine speeds. At $1000 \mathrm{rpm}$ and $2000 \mathrm{rpm}$, the increase in $r_{I / S}$ produces weaker swirl flow motions, as shown in Figure 6 (a) and (b). The tumble flow and cross tumble flow motions transfer to each other under the impact of the swirl flow motion, therefore showing reversed trends. At $1000 \mathrm{rpm}$, the TR gradually reduces while CTR increases with $r_{I / S}$. At $2000 \mathrm{rpm}$, the TR gradually increases while CTR decreases with $r_{I / S}$. As the engine speed increases to $3000 \mathrm{rpm}$, the smallest $r_{I / S}$ of 0.68 leads to significantly slower scavenging flow rate and in turn weakens in-cylinder flow motions. The TR increases with $r_{I / S}$ and CTR peaks at $r_{I / S}$ of 1.02 , as shown in Figure 6 (c).

Overall, the design with smallest $r_{I / S}$ of 0.68 leads to smaller SR, TR and CTR at $3000 \mathrm{rpm}$, which slows down the fuel/air mixing at this high engine speed. The design with $r_{I / S}$ of 1.02 produces sufficient flow motions at different engine speeds.
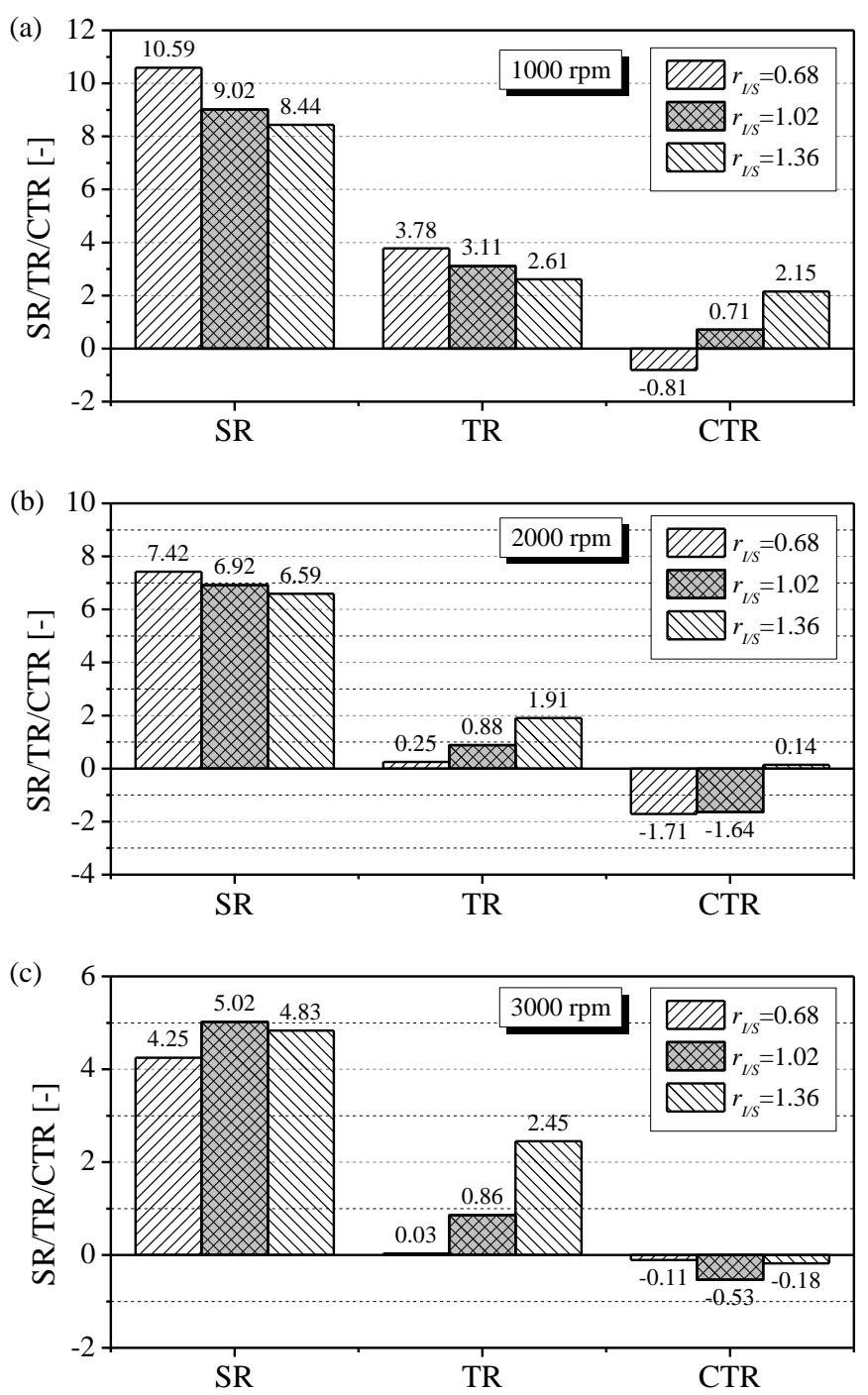

Figure 6. Effect of $r_{I / S}$ on in-cylinder flow motions (@ $280{ }^{\circ} \mathrm{CA}$ ) at (a) 1000 rpm, (b) $2000 \mathrm{rpm}$ and (c) $3000 \mathrm{rpm}$. 


\section{Effect of the radius of the round $\left(r_{R}\right)$}

In this section, the effect of the radius of the round $\left(r_{R}\right)$ on the scavenging process is investigated and the corresponding design parameters of the intake plenum are listed in Table 4.

Table 4.Intake plenum designs for the study on $r_{R}$.

\begin{tabular}{|l|l|l|l|l|l|}
\hline Case no. & $r_{I / S}[-]$ & $r_{R}[\mathbf{m m}]$ & $r_{S / C}[-]$ & $\alpha_{I / E}\left[{ }^{0}\right]$ & $r_{B / P L}[-]$ \\
\hline$\# 4$ & 1.02 & w/o & 0.84 & 180 & 8 \\
\hline$\# 5$ & 1.02 & $\mathbf{6 0}$ & 0.84 & 180 & 8 \\
\hline$\# 6$ & 1.02 & $\mathbf{1 0 0}$ & 0.84 & 180 & 8 \\
\hline
\end{tabular}

Figure 7 compares the scavenging performances with different radius of the round connecting the inlet pipe and scavenge chamber under different engine speeds. The radius of the rounding $\left(r_{R}\right)$ has little impact on the scavenging performances at the low engine speed of $1000 \mathrm{rpm}$. At $2000 \mathrm{rpm}$, a larger $r_{R}$ leads to slightly higher DR and CE. However, as the engine speed increases to $3000 \mathrm{rpm}$, the largest $r_{R}$ produces the lowest DR and CE. The $r_{R}$ shows little impact on the $\mathrm{SE}$ at different engine speeds.
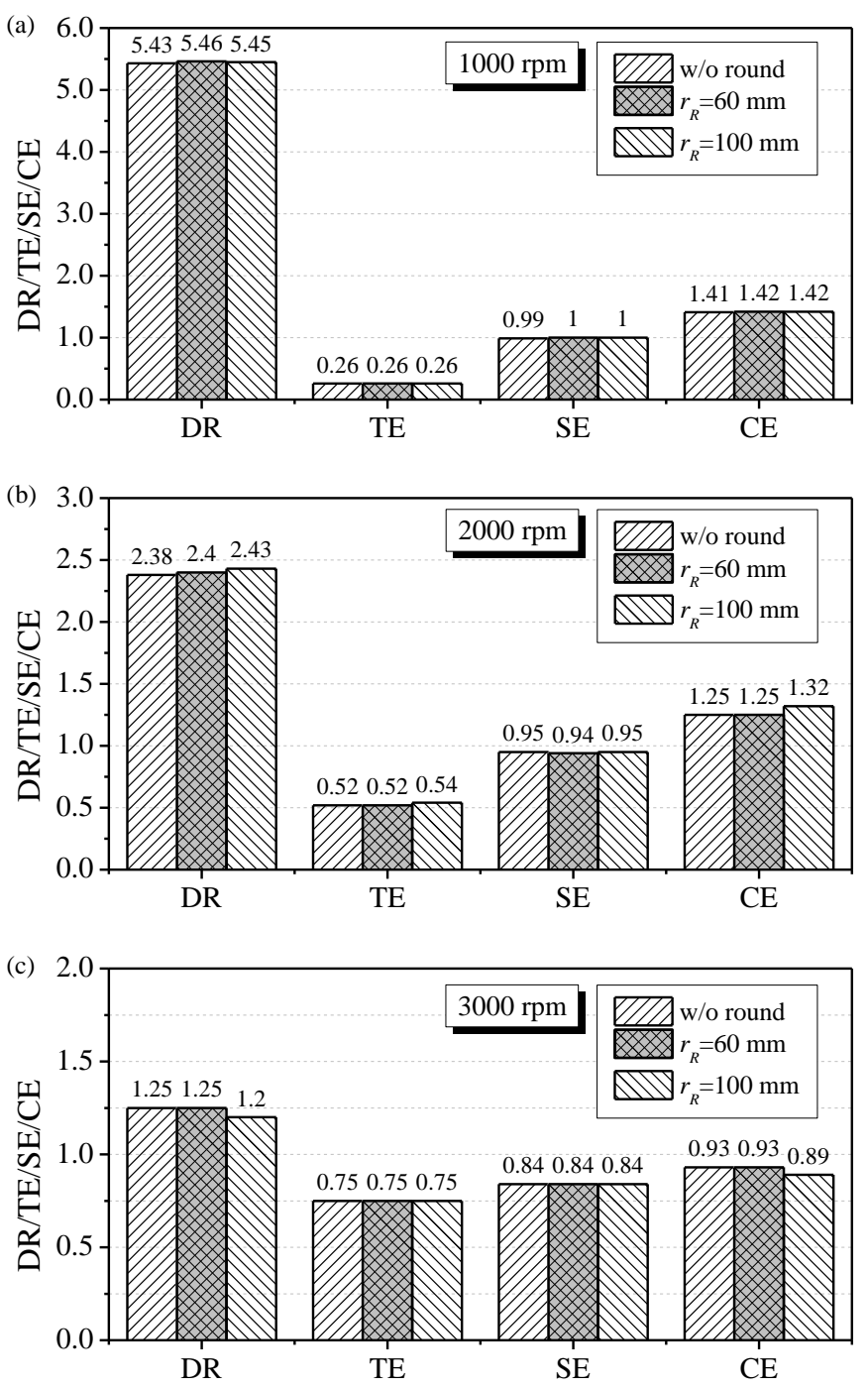

Figure 7. Effect of $r_{R}$ on scavenge performances at (a) $1000 \mathrm{rpm}$, (b) $2000 \mathrm{rpm}$ and (c) $3000 \mathrm{rpm}$.

Page 6 of 16
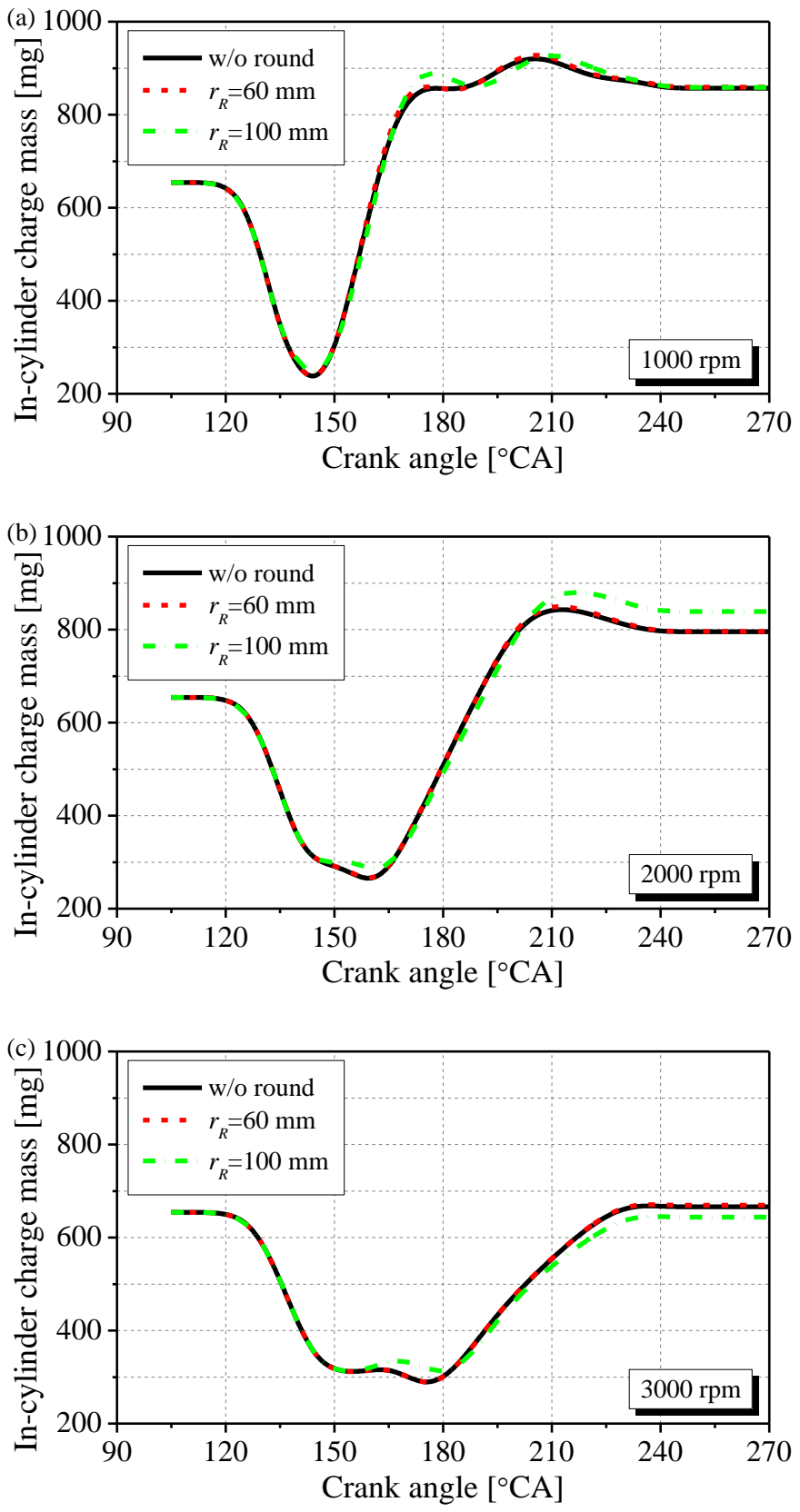

Figure 8. In-cylinder charge mass profiles for different $r_{R}$ at (a) $1000 \mathrm{rpm}$, (b) $2000 \mathrm{rpm}$ and (c) $3000 \mathrm{rpm}$.

At $1000 \mathrm{rpm}$, the final in-cylinder charge mass is almost the same for different $r_{R}$, as shown in Figure 8 (a). At $2000 \mathrm{rpm}$, a larger $r_{R}$ leads to higher peak in-cylinder charge mass due to smooth flow from inlet pipe to the scavenge chamber. This in turn leads to higher CE as shown in Figure 7 (b). However, as the engine speed increases to $3000 \mathrm{rpm}$, the increase in the in-cylinder charge mass after TDC is slowest for the largest $r_{R}$ of $100 \mathrm{~mm}$ and the final in-cylinder charge mass is also the lowest, as shown in Figure 8 (c). The main reason is the stronger air dynamics in the intake plenum at high engine speeds that the flow jets interact with each other and limit the air flow. Figure 9 shows the section views of the velocity vector and magnitude crossing the center of intake plenum. As shown in the figure, the flow flux at the scavenge ports close to inlet pipe is relatively higher due to the guidance by the inlet pipe compared to the design with $r_{R}$ of $100 \mathrm{~mm}$. For a large $r_{R}$ design, the main flow 
from inlet pipe would be smoothly distributed into two flows in the channel on both sides of the intake plenum. These two strong flows would finally counteract at the end of channel, which leads to lower velocity field in the intake plenum, as shown in Figure 9, and in turn inhibits the charging process. This in turn leads to lower DR and also CE.
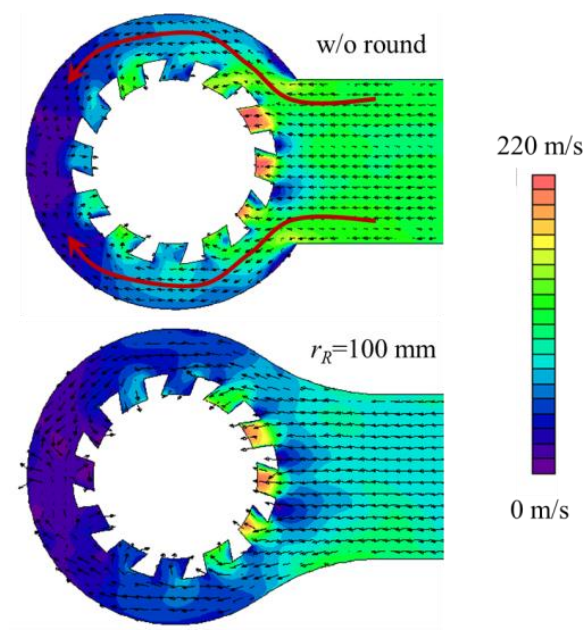

$0 \mathrm{~m} / \mathrm{s}$

Figure 9. The velocity vector and magnitude distributions at $185{ }^{\circ} \mathrm{CA}$ for intake plenum design without round and $r_{R}$ of $100 \mathrm{~mm}$ at $3000 \mathrm{rpm}$.

As shown in Figure 10, the intake plenum design without the round produces the highest swirl flow motion at all engine speeds. The other two designs with the round design lead to slightly lower SR. The trade-off between the tumble ratio and cross tumble ratio is observed among different designs at all engine speeds.
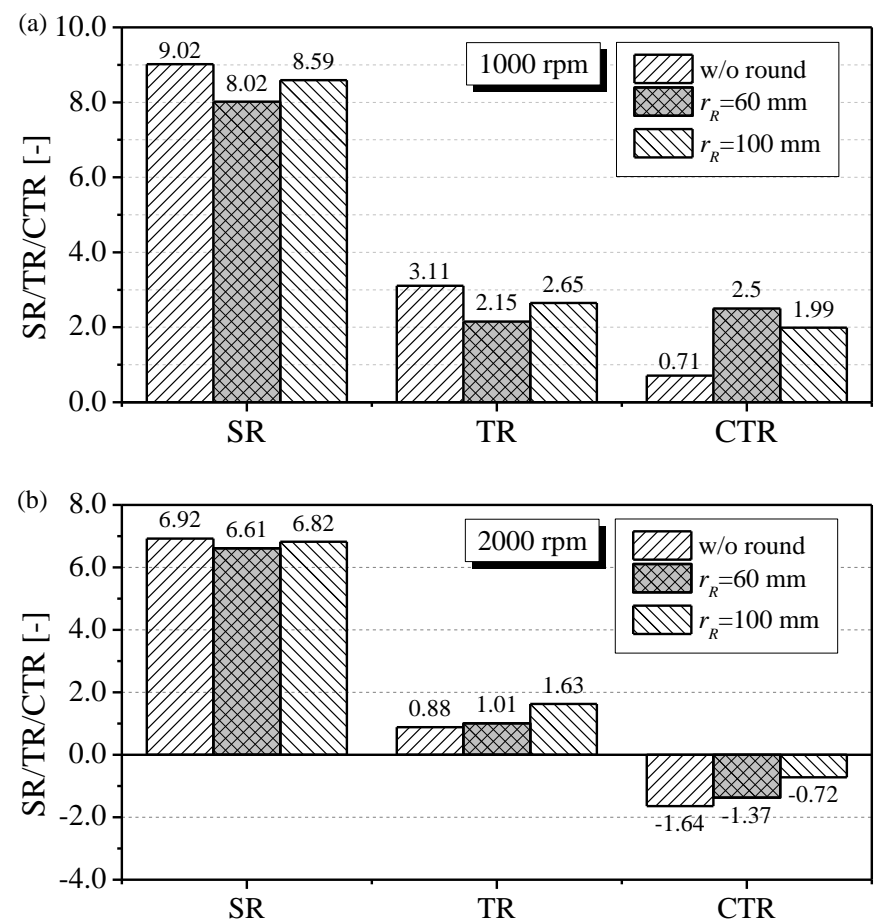

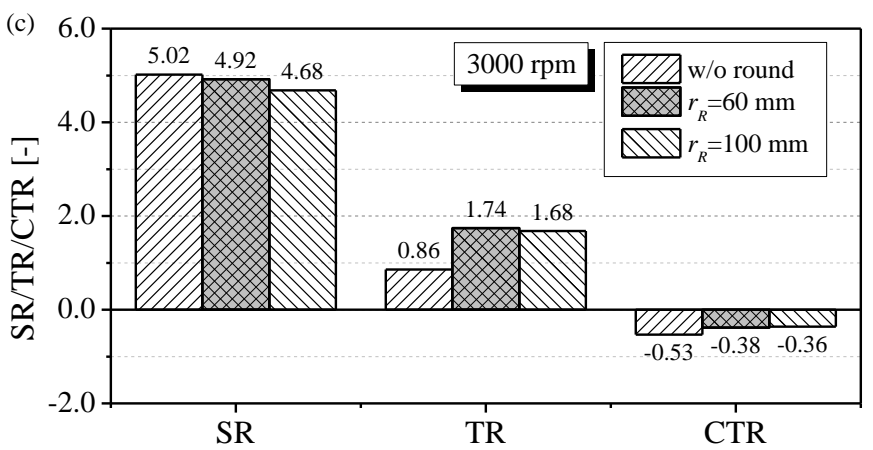

Figure 10. Effect of $r_{R}$ on in-cylinder flow motions (@280 ${ }^{\circ} \mathrm{CA}$ ) at (a) 1000 rpm, (b) $2000 \mathrm{rpm}$ and (c) $3000 \mathrm{rpm}$.

\section{Effect of the ratio of the scavenge chamber volume to the cylinder displacement volume $\left(r_{S / C}\right)$}

In this section, the effect of the ratio of the scavenge chamber volume to the cylinder displacement volume $\left(r_{S / C}\right)$ on the scavenging process is investigated and the corresponding design parameters of the intake plenum are listed in Table 5.

Table 5.Intake plenum designs for the study on $r_{S / C}$.

\begin{tabular}{|l|l|l|l|l|l|}
\hline Case no. & $r_{I / S}[-]$ & $r_{R}[\mathrm{~mm}]$ & $r_{S / C}[-]$ & $\alpha_{I / E}\left[{ }^{0}\right]$ & $r_{B / P L}[-]$ \\
\hline$\# 7$ & 1.02 & 60 & $\mathbf{0 . 8 4}$ & 180 & 8 \\
\hline$\# 8$ & 1.02 & 60 & $\mathbf{1 . 7 6}$ & 180 & 8 \\
\hline$\# 9$ & 1.02 & 60 & $\mathbf{3 . 0 2}$ & 180 & 8 \\
\hline
\end{tabular}

The DR is gradually increased with $r_{S / C}$, which is more pronounced at high engine speed, as shown in Figure 11. At low engine speed, the larger scavenge chamber on the one hand would trap more residual gas in the scavenge chamber due to the larger volume, reducing the SE slightly and also contributing to the slightly lower CE. On the other hand the increased scavenge chamber volume also increases the intake resistance, which contributes to the slower charging process and lower final in-cylinder mass, as well as CE.

As the engine speed increases to $2000 \mathrm{rpm}$, a larger scavenge chamber volume leads to better scavenge performances. The DR and SE monotonously increase with the scavenge chamber volume. However, the slower charging process leads to slightly lower final incylinder charge mass, as well as $\mathrm{CE}$, for the largest scavenge chamber with $r_{S / C}$ of 3.02 compared to that with $r_{S / C}$ of 1.76 .

At the highest engine speed of $3000 \mathrm{rpm}$, a larger scavenge chamber design shows improved scavenging performance. The DR, SE and $\mathrm{CE}$ are gradually increased with $r_{S / C}$. 

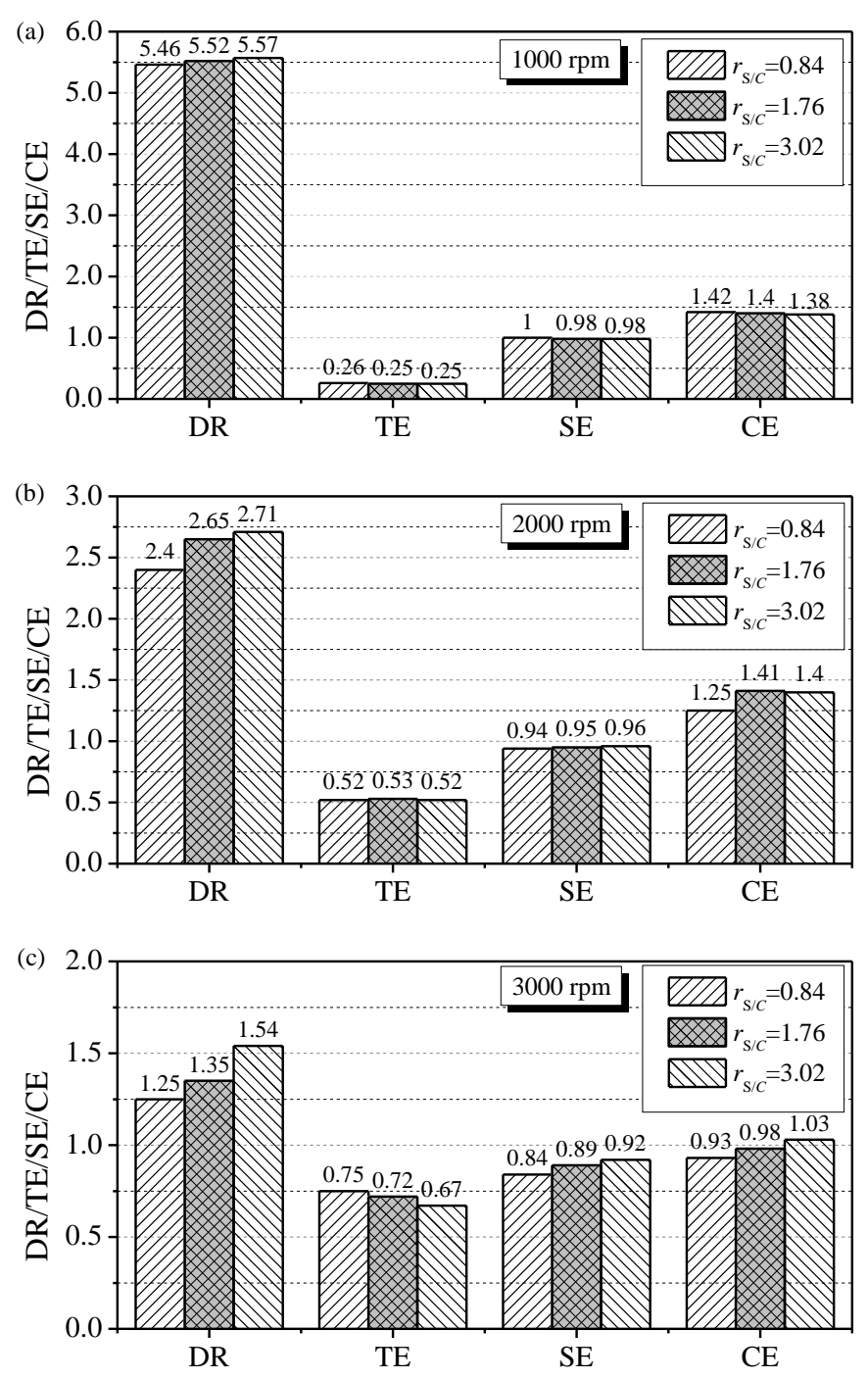

Figure 11. Effect of $r_{S / C}$ on scavenge performances at (a) $1000 \mathrm{rpm}$, (b) 2000 rpm and (c) $3000 \mathrm{rpm}$.

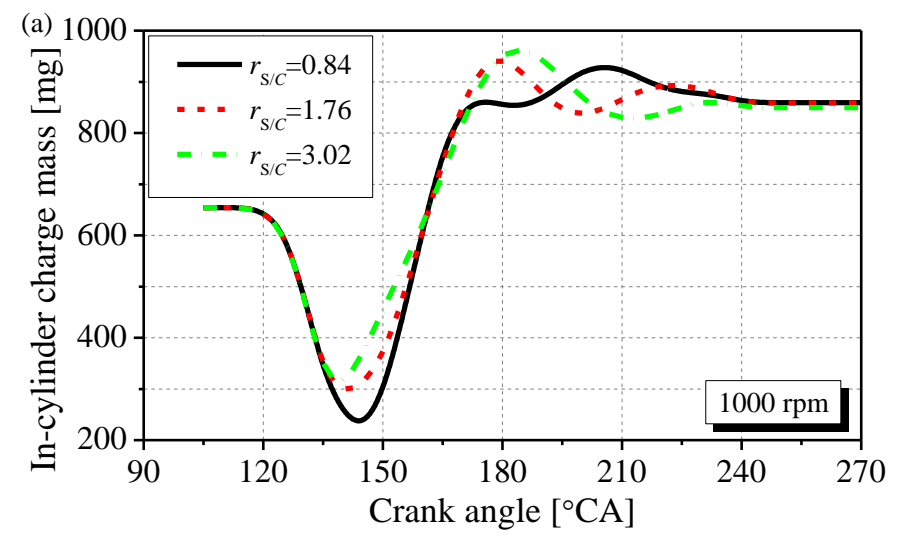

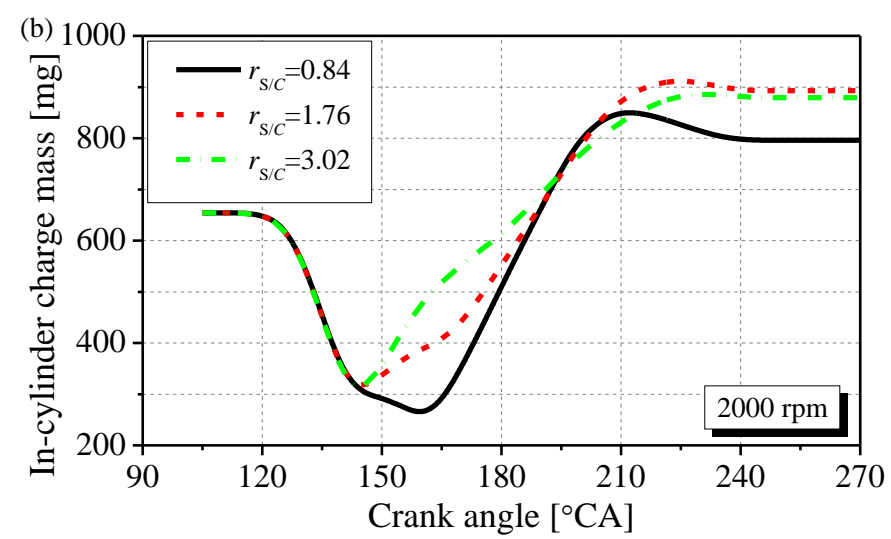

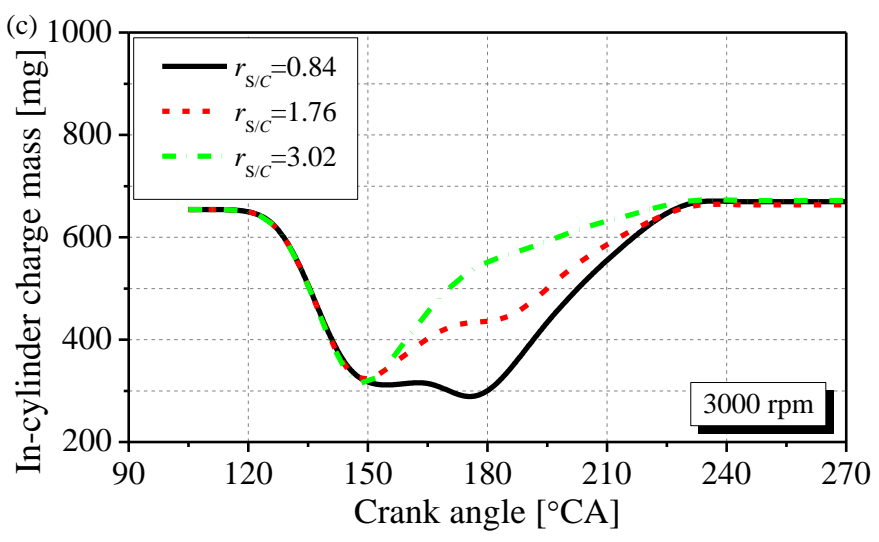

Figure 12. In-cylinder charge mass profiles for different $r_{S / C}$ at (a) $1000 \mathrm{rpm}$, (b) $2000 \mathrm{rpm}$ and (c) $3000 \mathrm{rpm}$.

As seen from Figure 13 (a) that a smaller scavenge chamber leads to earlier charge short-circuiting phenomenon at $3000 \mathrm{rpm}$. Therefore, the scavenge performance with a small scavenge chamber would be significantly deteriorated at high engine speeds. Figure 13 (b) shows section views of RGF distributions for the design with $r_{S / C}$ of 0.84 and 3.02. It is noted that the intake flow jets are significantly stronger at the scavenge ports close to the inlet pipe, which leads to asymmetric air flow path in the cylinder for a small scavenge chamber design. This in turn leads to the earlier charge shortcircuiting. In comparison, a larger scavenge chamber volume can produce symmetric intake flow path and delay the short circuiting, which significantly improve the scavenge performances at high engine speeds. 

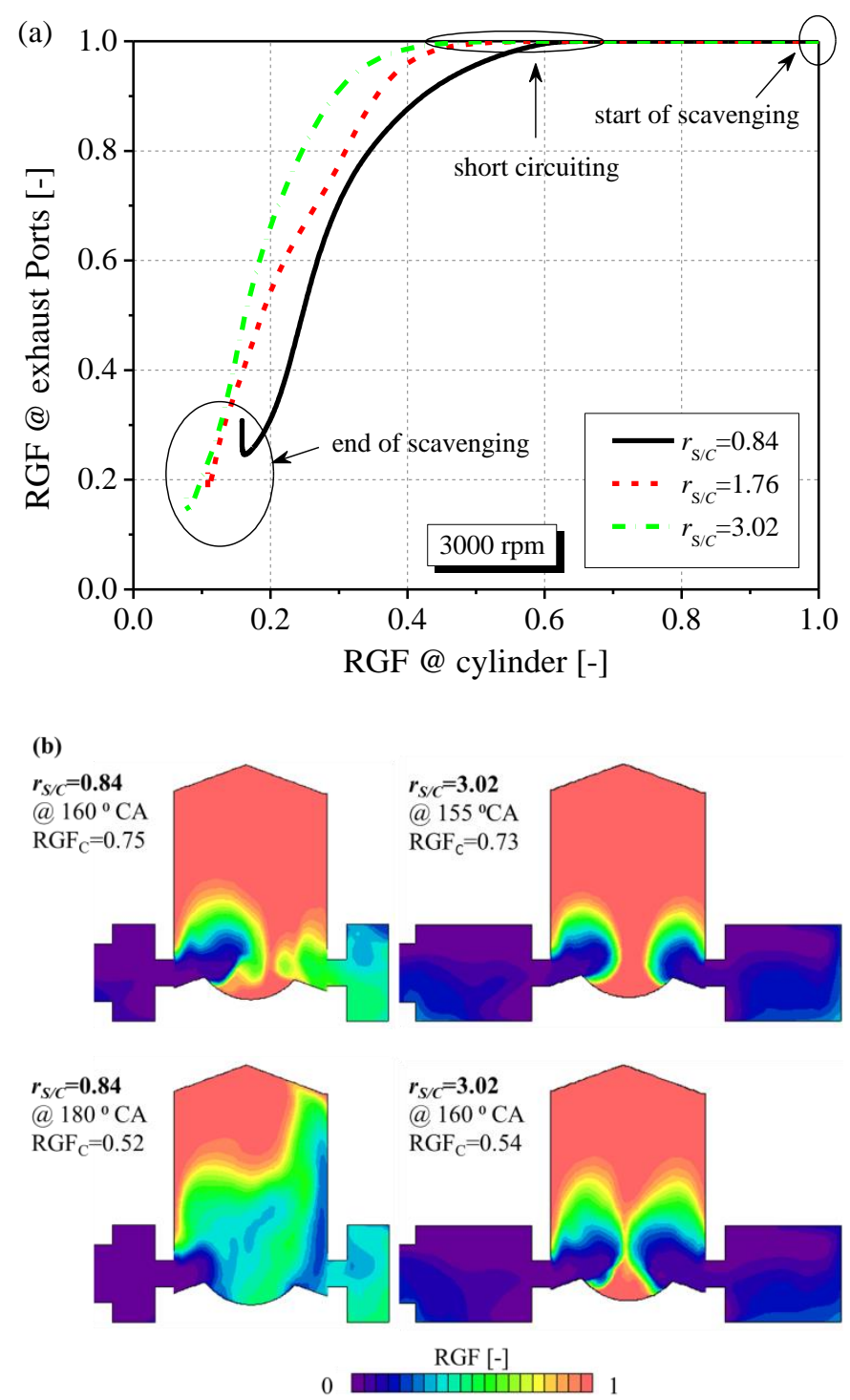

Figure 13. (a) The residual gas fraction (RGF) profiles in the cylinder and exhaust ports and (b) the corresponding RGF distributions at different crank angles at $3000 \mathrm{rpm}$ with different $r_{S / C}$.

Although the scavenge chamber volume shows impact on SR, TR and CTR, as shown in Figure 14, the flow motions are thought to be sufficient to enhance the fuel/air mixing for each design at 1000 and $2000 \mathrm{rpm}$. As the engine speed increases to $3000 \mathrm{rpm}$, both SR and TR shows a sharp decreasing trend with $r_{S / C}$, while the increase of CTR is slight. Therefore, the in-cylinder flow motions are a little weaker for a large scavenge chamber design with $r_{S / C}$ of 3.02 at a high engine speed.
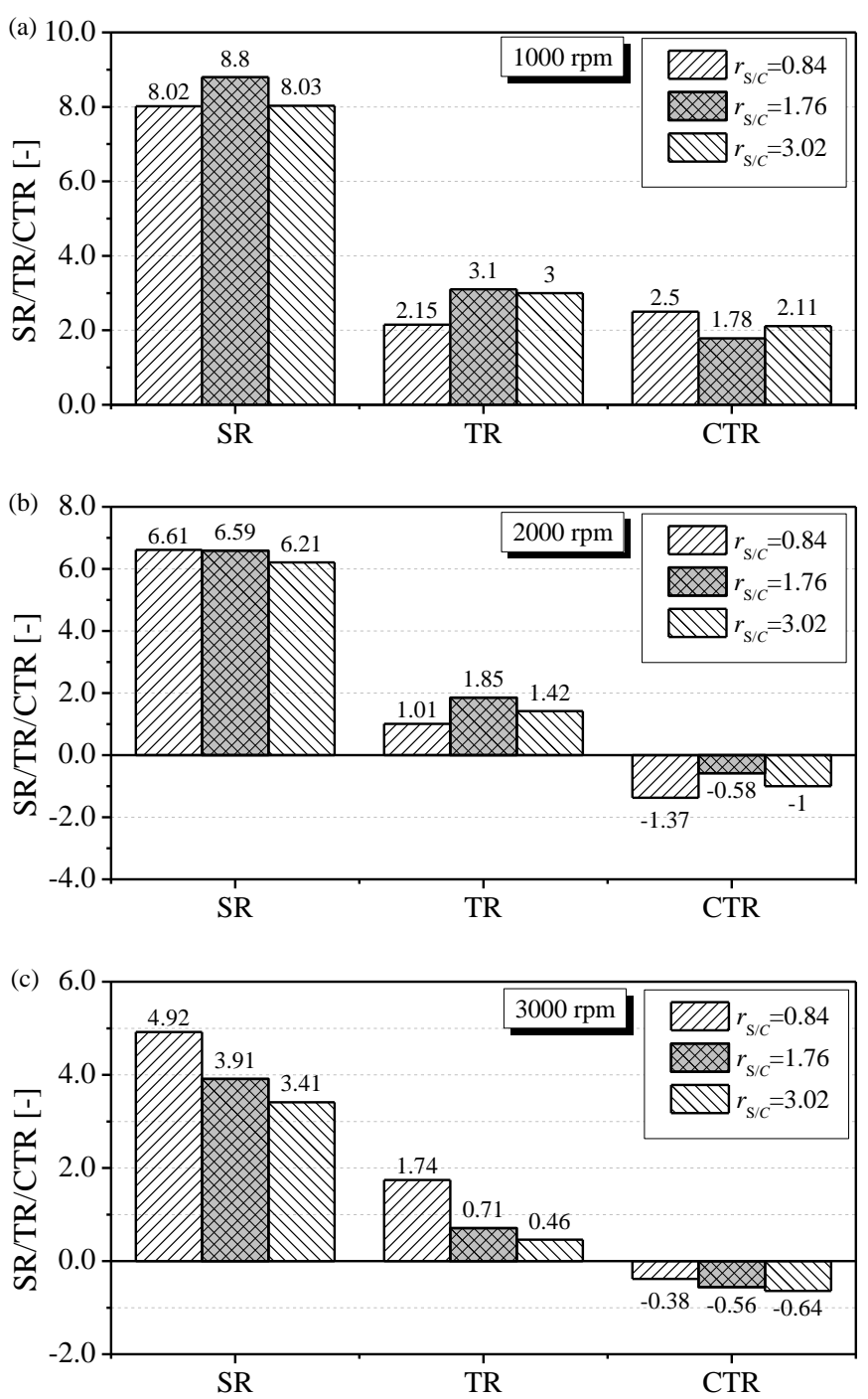

Figure 14. Effect of $r_{S / C}$ on in-cylinder flow motions (@ $280{ }^{\circ} \mathrm{CA}$ ) at (a) 1000 rpm, (b) $2000 \mathrm{rpm}$ and (c) $3000 \mathrm{rpm}$.

\section{Effect of the angle between the inlet pipe and exhaust pipe $\left(\alpha_{1 / E}\right)$}

In this section, the effect of the angle between the inlet pipe and exhaust pipe $\left(\alpha_{I / E}\right)$ on the scavenging process is investigated and the corresponding design parameters of the intake plenum are listed in Table 6.

Table 6.Intake plenum designs for the study on $\alpha_{I / E}$.

\begin{tabular}{|l|l|l|l|l|l|}
\hline Case no. & $r_{I / S}[-]$ & $r_{R}[\mathrm{~mm}]$ & $r_{S / C}[-]$ & $\boldsymbol{\alpha}_{I / E}\left[{ }^{0}\right]$ & $r_{B / P L}[-]$ \\
\hline$\# 10$ & 1.02 & 60 & 0.84 & $\mathbf{1 8 0}$ & 8 \\
\hline$\# 11$ & 1.02 & 60 & 0.84 & $\mathbf{9 0}$ & 8 \\
\hline$\# 12$ & 1.02 & 60 & 0.84 & $\mathbf{0}$ & 8 \\
\hline
\end{tabular}

As shown in Figure 15 (a), the position of the inlet pipe shows little impact on the scavenging performances at a low engine speed of $1000 \mathrm{rpm}$. As the engine speed increases to $2000 \mathrm{rpm}$, the 
deterioration of the DR is significant for the design with $\alpha_{I / E}$ of $90^{\circ}$, and the design with intake and exhaust pipes at the same side $\left(\alpha_{I / E}=0^{\circ}\right)$ shows highest DR. However, the SE and CE are less affected by $\alpha_{I / E}$. At $3000 \mathrm{rpm}$, the impact of intake plenum design on the scavenge performance becomes more apparent. The poorest scavenge performance is produced by the lowest DR, SE and CE for the design with $\alpha_{I / E}$ of $90^{\circ}$ while it is best with the $\alpha_{I / E}$ of $0^{\circ}$, as shown in Figure 15 (c).

The in-cylinder charge mass profiles in Figure 16 indicate that the incylinder mass increases much faster after $150{ }^{\circ} \mathrm{CA}$ with $\alpha_{I / E}$ of $0^{\circ}$ at $3000 \mathrm{rpm}$, which leads to highest DR, SE and CE. In order to match the pentroof cylinder head, the current piston top design is asymmetric, which renders earlier opening of the scavenging ports at the exhaust sides. Therefore, the design with $\alpha_{I / E}$ of $0^{\circ}$ leads to a closer distance between the inlet pipe and the first opening scavenge ports and faster increase in the flow rate though the scavenging ports. As shown in Figure 17, the flow through the scavenge ports with $\alpha_{I / E}$ of $0^{0}$ is noticeably higher than the other two plenum designs, resulting in the higher scavenging performance.
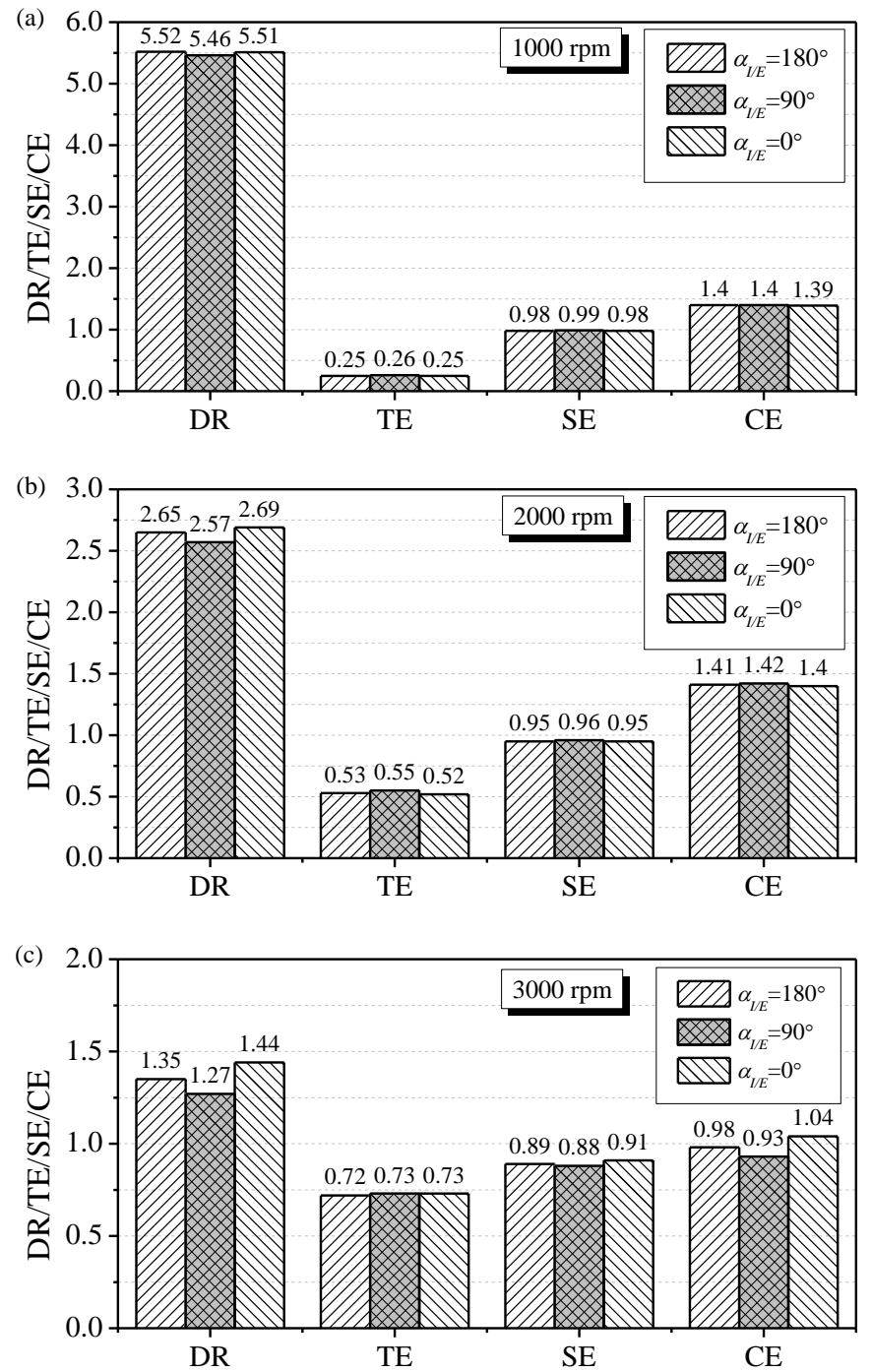

Figure 15. Effect of $\alpha_{I / E}$ on scavenge performances at (a) $1000 \mathrm{rpm}$, (b) 2000 rpm and (c) $3000 \mathrm{rpm}$.

Page 10 of 16
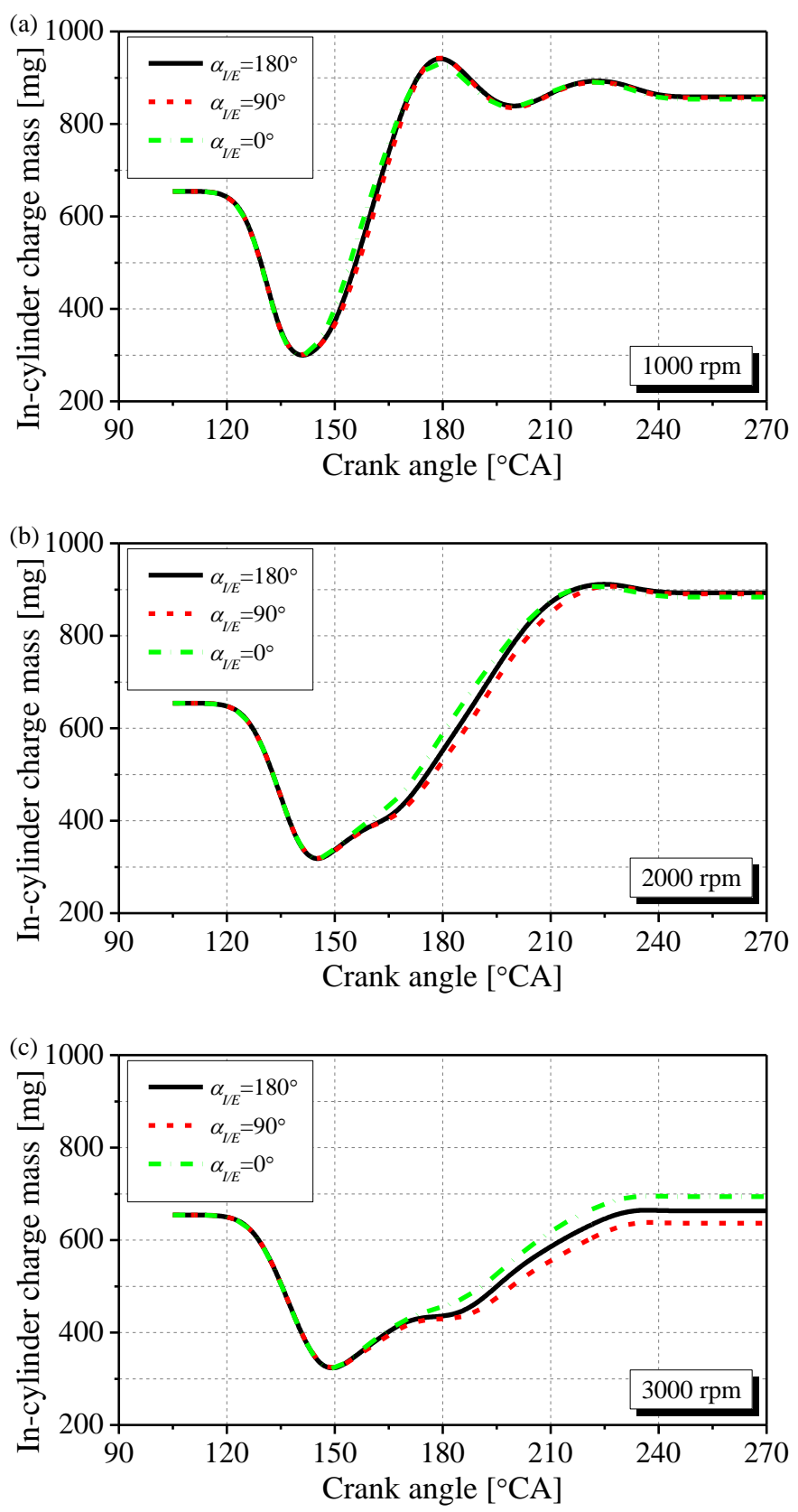

Figure 16. In-cylinder charge mass profiles for different $\alpha_{I / E}$ at (a) $1000 \mathrm{rpm}$, (b) $2000 \mathrm{rpm}$ and (c) $3000 \mathrm{rpm}$.

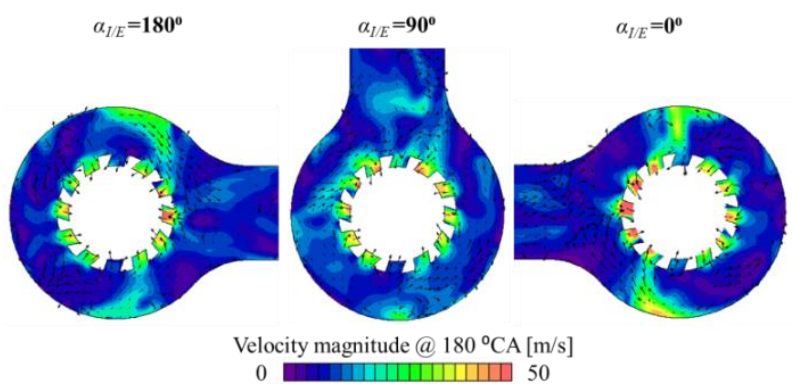

Figure 17. The velocity vector and magnitude distributions at $180{ }^{\circ} \mathrm{CA}$ for intake plenum design without round and $\alpha_{I / E}$ of $100 \mathrm{~mm}$ at $3000 \mathrm{rpm}$. 
As shown in Figure 18, the SR shows a decreasing trend with $\alpha_{I / E}$ at all engine speeds. As the in-cylinder tumble and cross tumble flow transfer to each other under the impact of the swirl flow motion, the vertical placement of the inlet pipe relative to the exhaust pipe can be used to effectively enhance the in-cylinder tumble flow (at 2000 and $3000 \mathrm{rpm}$ ) or cross tumble flow (at 1000 and $2000 \mathrm{rpm}$ ), as shown in Figure 18.
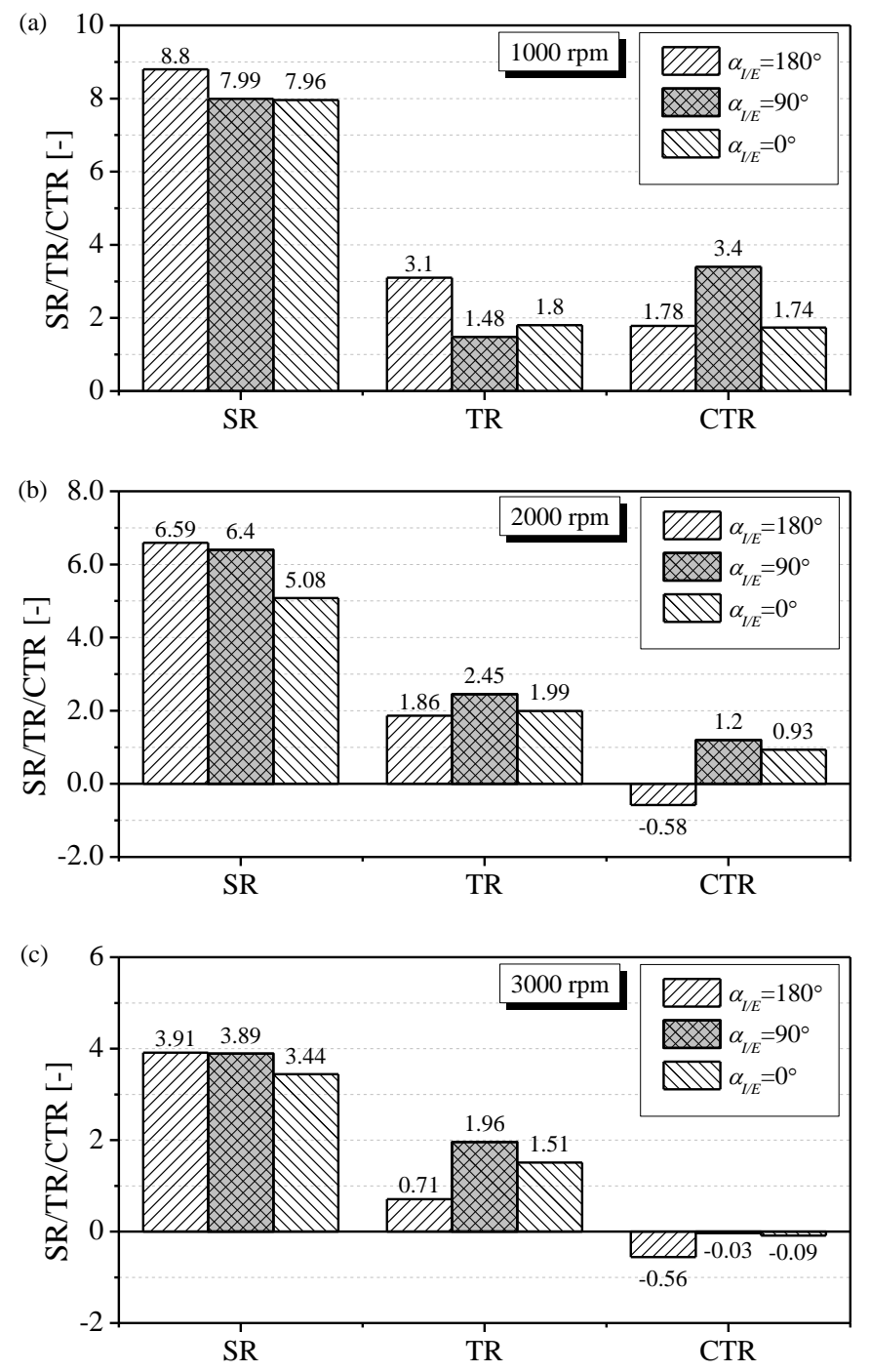

Figure 18. Effect of $\alpha_{I / E}$ on in-cylinder flow motions (@ $280^{\circ} \mathrm{CA}$ ) at (a) 1000 rpm, (b) $2000 \mathrm{rpm}$ and (c) $3000 \mathrm{rpm}$.

\section{Effect of the ratio of cylinder bore to the scavenge port length $\left(r_{B / P L}\right)$}

In this section, the effect of the cylinder bore to the scavenge port length (PL) in the radial direction $\left(r_{B / P L}\right)$ on the scavenging process is investigated to demonstrate the effect of scavenge port length $(P L)$ on the scavenging process. The corresponding design parameters of the intake plenum are listed in Table 7.

Overall, the port length $(P L)$ shows only slight impact on the scavenging performance even at high engine speed of $3000 \mathrm{rpm}$, as shown in Figure 19. However, it is noted in Figure 20 that the swirl flow motion is gradually enhanced as $r_{B / P L}$ decreases from 16 to 4 .
The shortest scavenge port with $5 \mathrm{~mm}$ port length $\left(r_{B / P L}=16\right)$ generate significantly lower SR at $3000 \mathrm{rpm}$. Figure 21 compares the velocity vector and magnitude distributions at $180{ }^{\circ} \mathrm{CA}$ for the intake plenum design with $r_{B / P L}$ of 16 and 4 at $2000 \mathrm{rpm}$. It is noted that the short port length design $\left(r_{B / P L}=16\right)$, compared to the long port design $\left(r_{B / P L}=4\right)$, shows very weak enhancement of the swirling flow from scavenging ports, thus leading to relatively lower in-cylinder swirl flow motion. Therefore, an intake plenum design with port length of at least $10 \mathrm{~mm}$ is preferred to achieve good mixing in the BUSDIG engine.

Table 7.Intake plenum designs for the study on $r_{B / P L}$.

\begin{tabular}{|l|l|l|l|l|l|}
\hline Case no. & $r_{I / S}[-]$ & $r_{R}[\mathrm{~mm}]$ & $r_{S / C}[-]$ & $\alpha_{I / E}\left[^{0}\right]$ & $r_{B / P L}[-]$ \\
\hline$\# 13$ & 1.02 & 60 & 0.84 & 180 & $\mathbf{1 6}$ \\
\hline$\# 14$ & 1.02 & 60 & 0.84 & 180 & $\mathbf{8}$ \\
\hline$\# 15$ & 1.02 & 60 & 0.84 & 180 & $\mathbf{4}$ \\
\hline
\end{tabular}
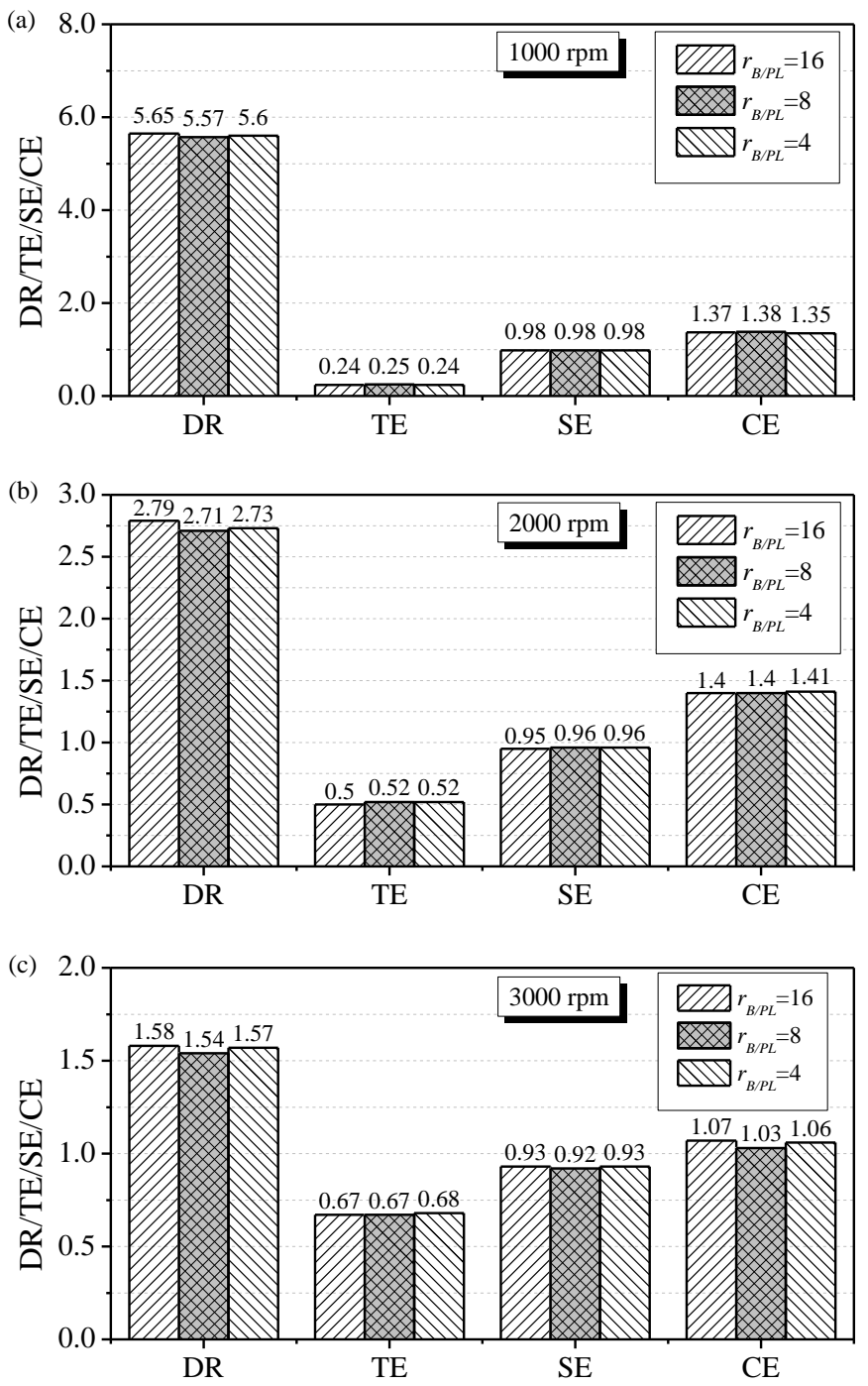

Figure 19. Effect of $r_{B / P L}$ on scavenge performances at (a) $1000 \mathrm{rpm}$, (b) 2000 rpm and (c) $3000 \mathrm{rpm}$. 

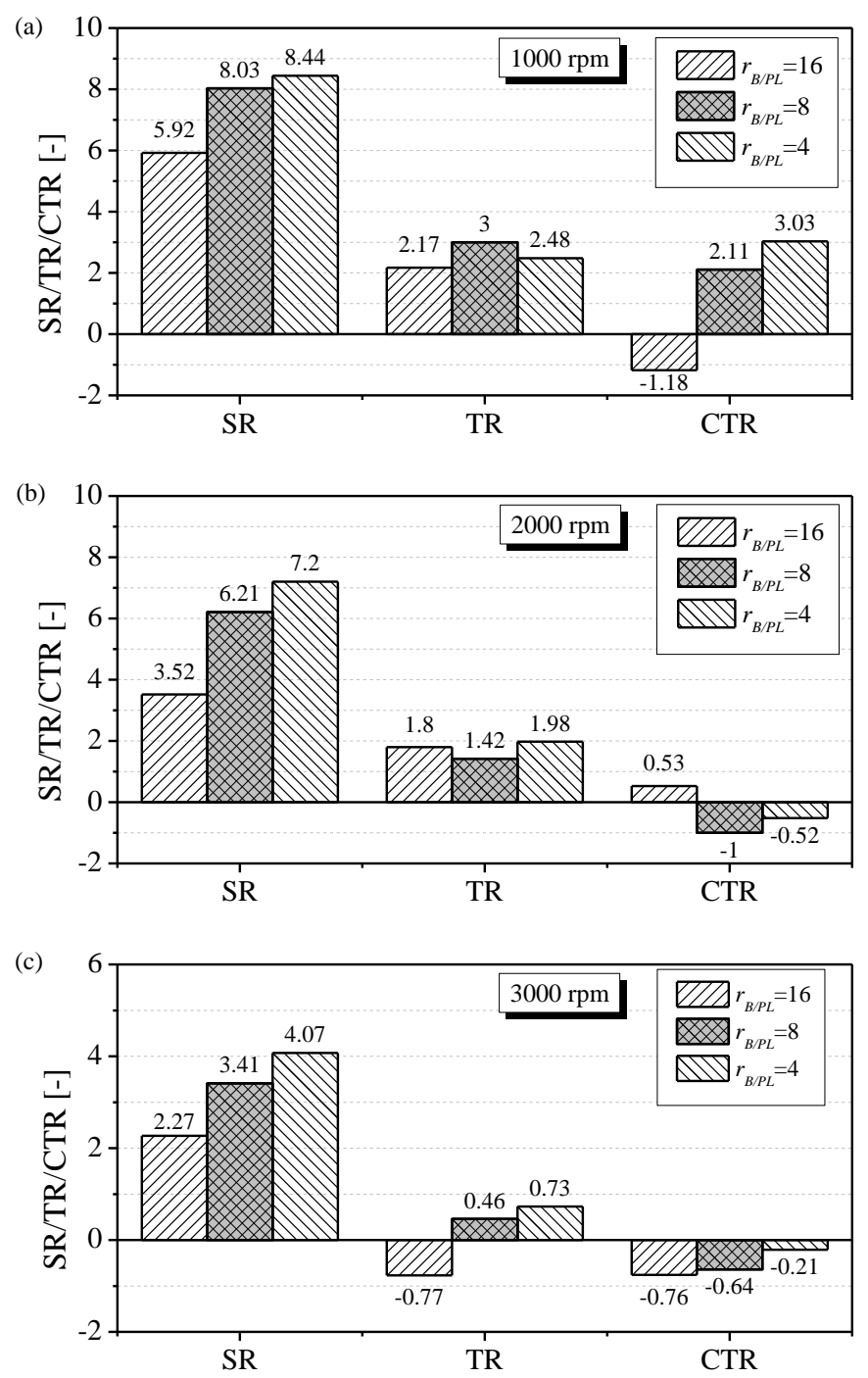

Figure 20. Effect of $r_{B / P L}$ on in-cylinder flow motions (@ $280{ }^{\circ} \mathrm{CA}$ ) at (a) 1000 rpm, (b) $2000 \mathrm{rpm}$ and (c) $3000 \mathrm{rpm}$.

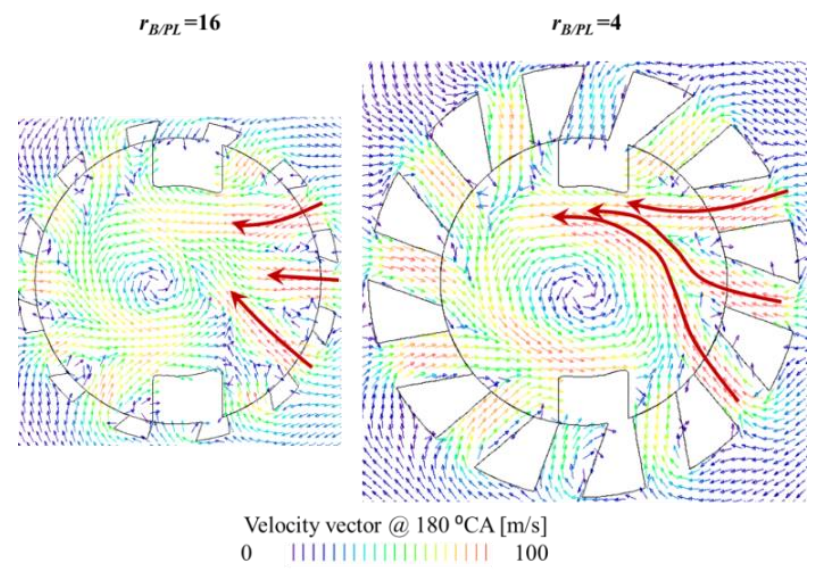

Figure 21 . The velocity vector and magnitude distributions at $180{ }^{\circ} \mathrm{CA}$ for intake plenum design with $r_{B / P L}$ of 16 and 4 at $2000 \mathrm{rpm}$.

\section{Conclusions}

In this study, three dimensional (3D) computational fluid dynamics (CFD) simulations were performed to understand the effect of intake plenum design on the scavenging process in a 2-stroke boosted uniflow scavenged direct injection gasoline (BUSDIG) engine. Five design parameters of the intake plenum, i.e. the ratio of the inlet area relative to the scavenge port area $\left(r_{I / S}\right)$, the radius of the round connecting the inlet pipe and the scavenge chamber $\left(r_{R}\right)$, the ratio of the scavenge chamber volume to the cylinder displacement volume $\left(r_{S / C}\right)$, the angle between the inlet pipe and exhaust pipe $\left(\alpha_{I / E}\right)$ and the ratio of bore to the scavenge port length $\left(r_{B / P L}\right)$, were investigated in detail under different engine speeds. The findings are summarized as follows:

1. Overall, the scavenging performance is best at the lower engine speed. The intake plenum design shows less impact on the scavenging performances at $1000 \mathrm{rpm}$. As the engine speed increases, the intake plenum design has more impact on the scavenging performance and the optimal design is defined by a trade-off between tumble ratio (TR) and cross tumble ratio (CTR).

2. The inlet area design with $r_{I / S}$ of 1.02 is preferred to maintain the optimal scavenging performances. The further increase of $r_{I / S}$ from 1.02 to 1.36 shows little improvement of the scavenging performance at high engine speeds.

3. A larger round design $\left(r_{R}\right)$ can hinder the scavenge performance at $3000 \mathrm{rpm}$ due to the strong interaction of the flow field in the intake plenum.

4. A larger scavenge chamber design with $r_{S / C}$ of 3.02 can improve the scavenging performances with small impact on the in-cylinder flow at high engine speeds.

5. The intake plenum design with $\alpha_{I / E}$ of $0^{\circ}$ leads to the best scavenge performance with the highest DR, SE and CE. The intake plenum design with $\alpha_{I / E}$ of $90^{\circ}$ can be used to enhance the in-cylinder tumble or cross tumble flow motions, although the scavenge performance is deteriorated at $3000 \mathrm{rpm}$.

6. The intake plenum with a short port length design leads to the weaker in-cylinder flow motion although it shows only slight impact on the scavenging performances. A port length of at least $10 \mathrm{~mm}$ is preferred to achieve good mixing in the BUSDIG engine.

\section{References}

1. Ma J. and Zhao H. "The Modeling and Design of a Boosted Uniflow Scavenged Direct Injection Gasoline (BUSDIG) Engine". SAE Technical Paper 2015-01-1970.

2. Laget O., Ternel C. and Thiriot J. et al. "Preliminary Design of a Two-Stroke Uniflow Diesel Engine for Passenger Car". Vol. 6.

3. Mattarelli E., Rinaldini C. A. and Baldini P. "Modeling and Experimental Investigation of a 2-Stroke GDI Engine for Range Extender Applications". SAE Technical Paper 2014-01-1672.

\section{Page 12 of 16}


4. Wang X., Ma J. and Zhao H. "Evaluations of Scavenge Port Designs for a Boosted Uniflow Scavenged Direct Injection Gasoline (BUSDIG) Engine by 3D CFD Simulations". SAE Technical Paper 2016-01-1049.

5. Abis A., Winkler F. and Schwab C. et al. "An Innovative TwoStroke Twin-Cylinder Engine Layout for Range Extending Application". SAE Technical Paper 2013-32-9133.

6. Hori H. "Scavenging Flow Optimization of Two-Stroke Diesel Engine by Use of CFD". SAE Technical Paper 2000-01-0903.

7. Vashishtha A., Rathinam B. and Delahaye L. et al. "Study of Intake Ports Design for Ultra Low Cost (ULC) Gasoline Engine Using STAR-CD"., SAE Technical Paper 2012-01-0407.

8. Blair G. P., Design and simulation of two-stroke engines. Society of Automotive Engineers Warrendale, PA: 1996.

9. Cd-adapco. "Methodology, STAR-CD VERSION 4.14, 2010".

10. Sjöberg M. and Dec J. E. "An Investigation of the Relationship Between Measured Intake Temperature, BDC Temperature, and Combustion Phasing for Premixed and DI HCCI Engines". SAE Technical Paper 2004-01-1900.

11 Wang X., Xie H. and Zhao H. Computational study of the influence of in-cylinder flow on spark ignition-controlled autoignition hybrid combustion in a gasoline engine. International Journal of Engine Research 2015; 16(5): 795-809.

\section{Contact Information}

Dr. Xinyan Wang

xinyan.wang@brunel.ac.uk

Centre for Advanced Powertrain and Fuel Research

Brunel University London, UK

UB8 3PH

\section{Acknowledgments}

The authors gratefully acknowledge the financial support by the Engineering and Physical Sciences Research Council (EPSRC). The data of this paper can be accessed from the Brunel University London data archive, figshare at https://brunel.figshare.com.

\section{Definitions/Abbreviations}

3D

$\alpha_{I / E}$

AIA

ATDC

BDC

BUSDIG

CE

CFD

CTR

DR

ED

EVC

EVO

$r_{B / P L}$

RGF

$r_{I / S}$

$\boldsymbol{r}_{R}$

$r_{S / C}$

SE

SPC

SPH

SPO

SOA

SR

TE

TR

VVA three-dimensional

the angle between the inlet pipe and exhaust pipe

axis inclination angle

after top dead center

bottom dead center

boosted uniflow scavenged direct injection gasoline

charging efficiency

computational fluid dynamics

cross tumble ratio

delivery ratio

exhaust duration

exhaust valve close

exhaust valve open

the ratio of bore to the scavenge port length

residual gas fraction

the ratio of the inlet area relative to the scavenge port area

The radius of the round connecting the inlet pipe and the scavenge chamber

the ratio of the scavenge chamber volume to the cylinder displacement volume

scavenging efficiency

scavenge port closing

scavenge port height

scavenge port opening

swirl orientation angle

swirl ratio

trapping efficiency

tumble ratio

variable valve actuation 
Dear Organizers and Reviewers,

Thank you for your kind comments and suggestions to the manuscript. We have modified the manuscript accordingly, and detailed corrections are listed below point by point. The black parts are the reviewers' comments, and the blue parts are our responses. All the revisions are highlighted in the manuscript using the red text.

We look forward to your positive response.

Sincerely,

Xinyan Wang

Brunel University London

\section{Reviewer 1:}

\section{Abstract: The abstract is too long and should be shortened.}

We have shortened the abstract.

2. Table 2: How you have assessed the boundary conditions like piston crown and cylinder liner temperatures using a 1D approach of WAVE? Applying this approach usually presumes some assumptions on these temperatures, but you used them as boundary conditions... Please explain in the text.

We did not use the 1D simulation to estimate the wall temperatures. The wall temperature of the cylinder head, piston top and cylinder liner were presumed according to the estimation proposed by M. Sjöberg et al (SAE 2004-01-1900). This has been explained in the text on Page 3.

\section{How the developed model was validated?}

As we are at the engine design stage, there is no available experimental data for the model validation at this moment. In this work, we reviewed the literatures on 2-stroke engine simulations and adopted the widely used numerical models (e.g. RANS, K- $\varepsilon$ RNG turbulence model) and numerical methods (e.g. PISO algorithm, spatial discretisation methods). In addition, we also performed the mesh sensitivity study to avoid the impact of mesh quality on simulation results as detailed in a previous paper [SAE 2016-01-1049].

\section{Conclusions: Please mention what are the most influencing design factors}

Thanks for the kind suggestions. However, as shown in the manuscript, there are several parameters to demonstrate the scavenging process and incylinder flow motions and each parameter has different range of values under different engine speeds. It is hard to explicitly drawn a conclusion on the most influencing design factors. Generally, a larger scavenge chamber $(\mathrm{rS} / \mathrm{C})$ can significantly improve the scavenge performances. The angle of inlet pipe $(\alpha \mathrm{I} / \mathrm{E})$ and port length can be used to effectively adjust the in-cylinder flow motions. These findings are included in the conclusions.

General remark: I think that the number of figures and tables can be reduced without losing useful information

Thanks for the kind suggestion. We put all these figures and tables to ensure a complete and thorough demonstration of the results and make the discussion and conclusions solid.

\section{Reviewer 2:}

17PFL-0642: Analysis of the effect of intake plenum design on the scavenging process in a 2-Stroke Boosted Uniflow Scavenged Direct Injection Gasoline (BUSDIG) Engine

Overall well written, a few minor grammatical errors that would be caught with a final proofread.

We have done the proofread of the whole manuscript.

It was discussed a bit in the metrics you used to quantify scavenging but a bit more in-depth discussion would be good. What metrics do you want high, what do you want low, etc-discuss this on page 4. How are you considering inducting the most fresh charge and losing the least fresh charge.

Page 14 of 16 
The DR represents the ability to deliver the fresh change from the intake system. The CE is used to quantify the retained the fresh charge in the cylinder after the scavenging. The TE represents the ability to retain the fresh charge in the cylinder relative to the total delivered charge. And the SE is used to demonstrate the retained fresh charge mass relative to the total trapped in-cylinder mass. Generally, higher DR, TE, SE and CE indicate higher scavenging performances. It has been added on Page 4.

The TE and SE $(\sim 1)$ would be very high if the engine can induce the most fresh charge and lose the least fresh charge. This is the ideal circumstance for the 2-stroke engine that the charge short circuiting is minimized or even avoided.

A few times the caption of your figure went onto the next page. Make sure your figure and caption stay on the same page.

This has been modified accordingly in the revised manuscript.

Figure 1 - geometry - is this a spatially feasible geometry based on size restriction in an engine compartment? Hard to visualize the full size I dimensions of the engine.

Figure 1 schematically shows the designs of the engine cylinder head, piston top and the scavenge ports. In the real engine application, the scavenge ports would not be so long as shown in Figure 1. These scavenge ports would be accommodated by the intake plenum. Therefore, it would be necessary to study the length of scavenge ports on the scavenging process, and this study has been included in this manuscript.

In the engine specifications section, you discuss operating conditions. You are essentially optimizing for these conditions - why these above conditions? Are they just typical values? Motivation for these values would be good.

In this study, in order to cover a broader range of engine speeds, three typical engine speeds from $1000 \mathrm{rpm}$ to $3000 \mathrm{rpm}$ have been studied. In terms of the other operating parameters, e.g. exhaust valve opening timing, scavenge port opening timing, boost pressure and so on, we selected the typical values basing on our previous work [SAE 2016-01-1049].

Typo in 'scavenge' in eqn 2

Thanks. It has been revised accordingly on Page 3.

For the parameters you are varying based on geometry - are these representative values / ranges? How did you determine?

The design parameters of the intake plenum studied in this work are believed to be realistic values for the future engine applications in terms of the size of the intake plenum and the difficulty of manufacturing. In order to clarify the effect of these designs on the scavenging process and in-cylinder flow motions, we carried out the detailed modelling studies to provide some guidance for the future engine applications.

\section{How did you validate your CFD model?}

As we are at the engine design stage, there is no available experimental data for the model validation at this moment. In this work, we reviewed the literatures on 2-stroke engine simulations and adopted the widely used numerical models (e.g. RANS, K- $\varepsilon$ RNG turbulence model) and numerical methods (e.g. PISO algorithm, spatial discretisation methods). In addition, we also performed the mesh sensitivity study to avoid the impact of mesh quality on simulation results as detailed in a previous paper [SAE 2016-01-1049].

\section{How did you chose the baseline values for Table 3 (and others) when you vary one of the geometrical parameters and keep others fixed.}

All the design parameters are defined in Section "Design of the intake plenum" and also schematically shown in Fig. 3. In Table 3, we studied the effect of the ratio of inlet area to the total scavenge port area. Therefore, we only adjust the height of the inlet pipe while keep the other parameters unchanged. In this case, the other design parameters can be kept fixed according to their definitions.

A lot of the differences in your bar charts - i.e. for examples Figure 4 at a certain speed - seem to have minimal differences case 1 - 2 - 3. Are these differences statistically significant? What is the uncertainty and confidence in these values? Would be good to include this info on all your bar charts. It seems that you are mostly discussing the influence of speed and grouping case 1,2,3 together in discussion but why don't you see any significant differences between case 1,2,3? Same comments apply to the other cases you considered... only for a few did you see actual cast to case differences at a fixed speed.

As a numerical simulation study, we do not have the statistical results. For each case (e.g. case 1), we have one simulation cycle to represent the outcome of the corresponding design. As the duration for the charge exchange is much shorter for a two stroke engine, the scavenging process shows higher sensitivity to the engine speeds, as shown in this study. At low engine speeds, the absolute duration for gas exchange is longer and the scavenging parameters shows lower sensitivity to the intake plenum design. However, as the engine speed increases to 3000 rpm, some intake plenum designs dramatically affect the scavenging performances. For example, as the rI/S increases from 0.68 to 1.02 , the DR increases by $15 \%$. The similar trends can be found for other intake plenum design parameters.

\section{Page 15 of 16}


Check equation numbering - you started again at eqn 1 on page 5 but you already had an eqn 1.

Thanks. It has been corrected.

\section{What does a negative CTR represent?}

A negative cross tumble ratio represents an opposite direction of the cross tumble flow shown in Fig. 1.

In your conclusions, you comment on preferred geometries based on each of the parameters you varied. How did you conclude these were best values? It seems that you didn't have significant differences case to case but only saw group differences (case 1, 2, 3) with speed so how can you conclude what was best? Discussing this in detail and how you came to the conclusions would greatly strengthen your work.

In this study, we designed different intake plenums to accommodate the scavenge ports for the BUSDIG engine. In order to verify the impact of the design of intake plenum on the scavenging process, simulations are performed and analysed in detail for each design parameter with other design parameters fixed. With this method, the impact of each parameter can be clarified. The results shown in this study have indicated that the scavenge performances are not sensitive to the intake plenum design at a low engine speed but become more sensitive at a higher engine speed. All these results are demonstrated and the reasons for each trend are also discussed for each parameter. Eventually, the optimal intake plenum for the engine application can be designed basing on these findings. 